\title{
Determinants of the Time Course of Facilitation at the Granule Cell to Purkinje Cell Synapse
}

\author{
Pradeep P. Atluri and Wade G. Regehr \\ Department of Neurobiology, Harvard Medical School, Boston, Massachusetts 02115
}

Short-term facilitation is a widely observed form of synaptic enhancement that is not well understood. Although presynaptic calcium has long been implicated in this process, its role is unclear, particularly at synapses in the mammalian brain. We tested the role of presynaptic residual free calcium $\left([\mathrm{Ca}]_{\mathrm{res}}\right)$ in facilitation of synapses between granule cells and Purkinje cells in rat cerebellar slices. Paired-pulse facilitation of synaptic currents resulted in an approximately 2.5 -fold enhancement that decayed with a time constant of $\sim 200 \mathrm{msec}$, as assessed by voltage-clamp recordings. Measurements of $[\mathrm{Ca}]_{\text {res }}$ using fluorescent calcium-sensitive indicators revealed that $[\mathrm{Ca}]_{\text {res }}$ decayed more rapidly than did facilitation. Manipulation of $[\mathrm{Ca}]_{\text {res }}$ dynamics by introducing EGTA into presynaptic termi- nals sped the decays of $[\mathrm{Ca}]_{\text {res }}$ and facilitation in a dosedependent manner. When $[\mathrm{Ca}]_{\text {res }}$ was reduced to a brief impulse lasting several milliseconds, facilitation was still present, although reduced in amplitude and duration. Facilitation decayed with an intrinsic time constant of $\sim 40 \mathrm{msec}$. These results suggest that facilitation at this synapse is produced by a calcium-driven process with a high affinity and a slow effective off-rate. A combination of $[\mathrm{Ca}]_{\text {res }}$ dynamics and the properties of a calcium-driven reaction determine the time course and amplitude of facilitation.

Key words: synaptic transmission; parallel fiber; presynaptic terminal; short-term enhancement; calcium; magnesium green; cerebellum
At many synapses, when two action potentials depolarize a presynaptic bouton in rapid succession, the second action potential releases more neurotransmitter than the first (Magleby, 1987; Zucker, 1989). This short-term enhancement of release that persists for tens to hundreds of milliseconds after a conditioning pulse is known as facilitation. Facilitation may play an important role in the synaptic coding of information contained in the temporal pattern of spike trains (Buonomano and Merzenich, 1995). In addition, characterizing facilitation has become an important way of studying synaptic transmission in the mammalian brain, and changes in the properties of paired-pulse facilitation are often taken to indicate a presynaptic change in neurotransmitter release (McNaughton, 1982; Schulz et al., 1994).

We are particularly interested in elucidating the mechanism of facilitation of synapses in the mammalian CNS. Residual free calcium $\left([\mathrm{Ca}]_{\text {res }}\right)$ that persists in the presynaptic terminal after termination of release has long been implicated in facilitation at synapses with large presynaptic terminals, such as the neuromuscular junction (NMJ) and the squid giant synapse (Katz and Miledi, 1968; Magleby, 1987; Bittner, 1989; Zucker, 1989; Liu and Stanley, 1995). Synapses in the mammalian CNS, at the NMJ, and in squid display facilitation with many common properties, which suggests that similar mechanisms are used by these synapses, but diversity in $[\mathrm{Ca}]_{\mathrm{res}}$ dynamics suggests that there may be important differences (Delaney et al., 1989; Swandulla et al., 1991; Delaney and Tank, 1994; Regehr et al., 1994; Regehr and Atluri, 1995; Feller et al., 1996). In large presynaptic terminals, buffered calcium diffusion plays an important role in

Received May 10, 1996; revised July 2, 1996; accepted July 3, 1996.

This work was supported by National Institutes of Health Grant R01-NS32405-01, a McKnight Scholars Award, and a Klingenstein Fellowship Award in the Neurosciences to W.R. We thank Bernardo Sabatini, Jeremy Dittman, A. Vyshedskiy, and J.-W. Lin for comments on this manuscript.

Correspondence should be addressed to Dr. Wade G. Regehr, Department of Neurobiology, Harvard Medical School, 220 Longwood Avenue, Boston, MA 02115. Copyright (C) 1996 Society for Neuroscience $0270-6474 / 96 / 165661-11 \$ 05.00 / 0$ determining $[\mathrm{Ca}]_{\mathrm{res}}$ at the release site on the time scale of facilitation (Yamada and Zucker, 1992; Winslow et al., 1994). In contrast, in small presynaptic boutons $(\sim 1 \mu \mathrm{m}$ in diameter) typical of the mammalian CNS, $[\mathrm{Ca}]_{\text {res }}$ dynamics is controlled primarily by calcium extrusion (Regehr and Atluri, 1995). This suggested to us the possibility that the action of calcium in facilitation and the properties of calcium-binding molecules involved in facilitation might well be tailored to match the fast, extrusion-limited $[\mathrm{Ca}]_{\mathrm{res}}$ dynamics characteristic of small presynaptic terminals associated with synapses in the mammalian brain.

The rapid spatial equilibration of calcium in these small boutons confers an important technical advantage for studying the role of calcium in facilitation: the ability to measure $[\mathrm{Ca}]_{\text {res }}$ dynamics on a tens of milliseconds time scale using calcium-sensitive fluorescent indicators. This has not been possible at the NMJ and squid synapses, because direct measurement of the time course of $[\mathrm{Ca}]_{\text {res }}$ cannot be made until calcium has spatially equilibrated by buffered diffusion. A conservative estimate of the equilibration time for calcium in a presynaptic bouton of radius $r$ can be obtained using the equation for the characteristic diffusion time of $\tau_{\mathrm{ch}}=r^{2} / 6 D$, and using a rather small effective diffusion coefficient for calcium, $D$, of $1 \times 10^{-7}$ $\mathrm{cm}^{2} / \mathrm{sec}$. We estimate the equilibration time of calcium to be $\sim 3$ msec for a $0.8-\mu \mathrm{m}$-diameter bouton, such as at the granule cell $\rightarrow$ Purkinje cell synapse, and $200 \mathrm{msec}$ for a 7- $\mu \mathrm{m}$-diameter terminal, such as at the crayfish NMJ.

Using modeling and indirect measures of $[\mathrm{Ca}]_{\mathrm{res}}$ dynamics, several hypotheses concerning the role of calcium in facilitation have emerged from the study of the NMJ and squid synapses (Charlton et al., 1982; Stanley, 1986; Bain and Quastel, 1992; Tanabe and Kijima, 1992; Yamada and Zucker, 1992; Blundon et al., 1993; Delaney and Tank, 1994; Kamiya and Zucker, 1994; Winslow et al., 1994; Liu and Stanley, 1995). Although there is agreement that facilitation is produced by calcium, there is uncertainty concerning the relative importance of calcium dynamics 
and the effective kinetics of calcium-activated processes in determining the time course of facilitation.

According to the simplest form of the residual calcium hypothesis, in facilitation calcium acts at the same low-affinity calcium binding sites involved in triggering release. In this model, the very high $(>100 \mu \mathrm{M})$ submembrane calcium levels that trigger release dissipate by diffusion into the terminal, and calcium unbinds rapidly from the low-affinity trigger sites to terminate release of neurotransmitter (Zucker, 1989). Calcium entering during a subsequent action potential summates with $[\mathrm{Ca}]_{\text {res }}$, enhancing release. If release were just proportional to the calcium concentration detected at the trigger, then the time course of facilitation should track the time course of decay of $[\mathrm{Ca}]_{\text {res; }}$; however, because of the power relation between calcium concentration and release (Dodge and Rahamimoff, 1967; Heidelberger et al., 1994; Heinemann et al., 1994), the decay of facilitation predicted by such a mechanism should be faster than the decay of $[\mathrm{Ca}]_{\mathrm{res}}$. Calcium may also remain bound to these sites, as in facilitation of calciumdependent bioluminescence in Obelia (Naranjo et al., 1994).

Another possibility is that $[\mathrm{Ca}]_{\text {res }}$ acts at a site with a higher calcium affinity than those involved in triggering release (Stanley, 1986; Delaney et al., 1989; Swandulla et al., 1991; Yamada and Zucker, 1992; Liu and Stanley, 1995). Some studies suggest that this site has rapid kinetics, with the time course of facilitation determined primarily by the time course of $[\mathrm{Ca}]_{\text {res }}$ (Kamiya and Zucker, 1994). Others favor a model with slow effective kinetics, so that the main determinant of the time course of facilitation is the kinetics of the calcium unbinding reaction or some consequence thereof (Blundon et al., 1993; Winslow et al., 1994).

Less is known about the role of calcium in setting the time course of facilitation at synapses with small presynaptic boutons. In frog tectal synapses, the magnitude but not the time course has been shown to be influenced by changes in $[\mathrm{Ca}]_{\text {res }}$ (Feller et al., 1996). Studies of synapses in the mammalian CNS have raised many questions regarding the role of $[\mathrm{Ca}]_{\mathrm{res}}$ in facilitation $(\mathrm{Wu}$ and Saggau, 1994) (see Discussion).

Here we examine the issue of what sets the time course of pairedpulse facilitation at the synapse between cerebellar granule cells and Purkinje cells. By using fast low-affinity calcium indicators, we are able to track changes in $[\mathrm{Ca}]_{\text {res }}$ on a time scale appropriate for the study of facilitation (Regehr and Atluri, 1995). In addition, we manipulated $[\mathrm{Ca}]_{\text {res }}$ transients to test further the role of calcium in facilitation. These studies establish that at this synapse the time course of facilitation is dictated in part by $[\mathrm{Ca}]_{\text {res }}$ dynamics and in part by the properties of a calcium-driven process with slow effective kinetics that is activated by modest calcium levels.

\section{MATERIALS AND METHODS}

Transverse slices (300 $\mu \mathrm{m}$ thick) were cut from the cerebellar vermis of 11- to 14-d-old rats, as described previously. Experiments were conducted at $24 \pm 0.5^{\circ} \mathrm{C}$, except for the experiments associated with Figure $3 B$, which were performed at $34 \pm 0.5^{\circ} \mathrm{C}$. The external solution $(2 \mathrm{ml} / \mathrm{min}$ flow rate) consisted of (in mM): $125 \mathrm{NaCl}, 2.5 \mathrm{KCl}, 2 \mathrm{CaCl}_{2}, 1 \mathrm{MgCl}_{2}, 26$ $\mathrm{NaHCO}_{3}, 1.25 \mathrm{NaH}_{2} \mathrm{PO}_{4}, 25$ glucose, and 0.02 bicuculline, bubbled with $95 \% \mathrm{O}_{2}$ and $5 \% \mathrm{CO}_{2}$.

For EGTA wash-in experiments, a $100 \mathrm{~mm}$ stock solution of EGTA-AM in dimethyl sulfoxide (DMSO) was aliquoted and frozen. Immediately before use, aliquots were diluted in external saline to final EGTA concentrations (in $\mu \mathrm{M}$ ) of 100,20 , or 1 , and DMSO concentrations (\%) of $0.1,0.02$, and 0.001 . Wash-ins were $15 \mathrm{~min}$ long, with flow rates of $2 \mathrm{ml} / \mathrm{min}$. To control for the effects of DMSO on facilitation, control experiments were performed with wash-in of DMSO alone. DMSO had no significant effect on the time course of facilitation in these experiments. Some experiments were also performed in which DMSO was present in the external solution, bathing the slice both before and after application of EGTA.

Detecting presynaptic calcium transients. Parallel fibers, made up of granule cell axons and presynaptic terminals, were labeled by local application of a solution containing the membrane-permeant forms of calcium indicators, as described previously (Regehr and Tank, 1991; Regehr and Atluri, 1995). The loading time was 3-5 min for mag-fura-5 $\mathrm{AM}, 3 \mathrm{~min}$ for fura-2 AM, and 8-10 min for magnesium green-AM (all from Molecular Probes, Eugene, OR). Experiments commenced $2 \mathrm{hr}$ after dye-loading. Parallel fiber tracts were stimulated extracellularly with an electrode placed in the molecular layer near the fill site. Fluorescence changes were measured in a $150-\mu \mathrm{m}$-diameter spot $400-700 \mu \mathrm{m}$ away from the stimulus site.

The filter set that was used for fura-2 and mag-fura-5 was a 380 HT 15 excitation, a 430DCLP02 dichroic, and a 510WB40 emission filter (Omega Optical, Brattleboro, VT), and for magnesium green, a 450-490 excitation, an FT510 dichroic, and an LP520 emission filter (Zeiss, Thornwood, NY). Fluorescence was detected with a photomultiplier tube (Hamamatsu HC124-06MOD; Hamamatsu, Bridgewater, NJ). Because calcium increases produce a decrease in fluorescence of fura- 2 and mag-fura-5 with $380 \mathrm{~nm}$ excitation, $\Delta F / F$ traces in Figure 2 have been inverted for these dyes.

Correction of fura-2 traces. As a consequence of its high affinity, fura-2 is known to distort the large calcium transients that occur in skeletal muscle (Konishi et al., 1988) and in small structures, such as parallel fiber presynaptic terminals (Regehr and Atluri, 1995). The degree of fura-2 saturation has been used to estimate the change in $[\mathrm{Ca}]_{\text {res }}$ produced by a single action potential (Regehr and Atluri, 1995; Sabatini and Regehr, 1995). In a straightforward extension of the reasoning of these previous studies, it is also possible to correct for the distortion of the time course of $\Delta F / F$ decay. The curve relating the number of spikes in a train, $N_{\text {spikes, }}$, to peak $\Delta F / F$ changes produced by $100 \mathrm{~Hz}$ trains, $(\Delta F / F)_{\text {peak }}$, was fit to a function of the form:

$$
N_{\text {spikes }}=\left(\frac{\Delta F}{F}\right)_{\text {peak }} \frac{K^{*}}{\left((\Delta F / F)_{\max }-(\Delta F / F)_{\text {peak }}\right)},
$$

where $\mathrm{K}^{*}$ and $(\Delta F / F)_{\max }$ are constants. The measured $\Delta F / F$ signal was then corrected for saturation of the indicator using the constants determined above and the following equation:

$$
[\mathrm{Ca}]_{\mathrm{res}}=\mathrm{c} \frac{\Delta F}{F} \frac{K^{*}}{\left((\Delta F / F)_{\max }-\Delta F / F\right)},
$$

where $\mathrm{c}$ is a constant.

The similarity of the time course of calcium decay for the corrected fura-2 transients and the low-affinity calcium indicators (see Fig. 2) supports the view that the time course of $[\mathrm{Ca}]_{\text {res }}$ decay is reported faithfully by mag-fura- 5 and magnesium green. Although the procedure described above corrects for the distortion produced by steady-state saturation of the indicator, it does not correct for dye kinetics (Regehr and Atluri, 1995).

Measuring synaptic currents. Whole-cell recordings of Purkinje neurons were obtained as described previously (Regehr and Mintz, 1994), using $0.9-1.5 \mathrm{M} \Omega$ glass pipettes containing an internal solution of (in $\mathrm{mM}$ ): 35 CsF, $100 \mathrm{CsCl}$, 10 EGTA, 10 HEPES, and 0.1 D600, pH 7.3 with CsOH. The access resistance $(<5 \mathrm{M} \Omega$ after series resistance compensation) and leak current $(0 \mathrm{pA}$ to $-200 \mathrm{pA})$ were monitored continuously.

Parallel fibers were stimulated extracellularly with a bipolar electrode placed in the molecular layer several hundred micrometers from the recording electrode. The resulting excitatory postsynaptic current (EPSC) decayed with a time constant of $5-7 \mathrm{msec}$ at $24^{\circ} \mathrm{C}$ and $3-5 \mathrm{msec}$ at $34^{\circ} \mathrm{C}$. Low stimulus intensities were used to keep synaptic currents small and the resulting voltage errors arising from uncompensated series resistance below $4 \mathrm{mV}$.

Facilitation was computed for each trial according to the equation $100 \times(A 2-A 1) / A 1$, where $A 1$ and $A 2$ are the peak amplitudes of the unfacilitated and facilitated synaptic currents, respectively. Similar results were obtained when averages of trials were used. At short interpulse intervals $(\leq 30 \mathrm{msec})$, the test EPSC was superimposed on the conditioning EPSC. For these trials, the waveform of the conditioning EPSC was subtracted from the superimposed test EPSC before determination of the maximum amplitude of the test EPSC.

Data acquisition and analysis. Outputs of the photomultiplier tube and Axopatch 200A were filtered at $1 \mathrm{kHz}$ with a model 900C9L8L 8-pole 


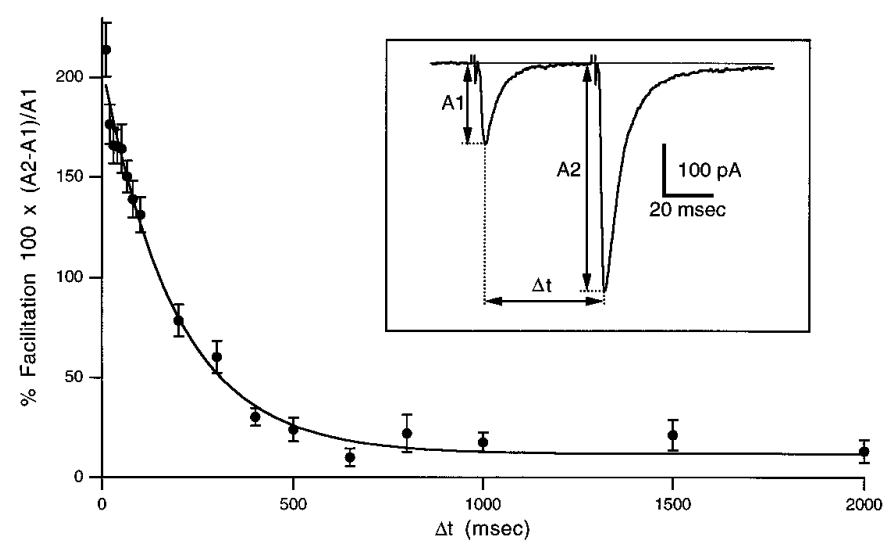

Figure 1. Paired-pulse facilitation at the granule cell to Purkinje cell synapse. Percentage facilitation as a function of interstimulus interval. Points are averages of 19 trials \pm SEM. Inset, Synaptic currents evoked by extracellular stimulation with stimulus pulses separated by $\Delta t=50 \mathrm{msec}$; the trace is an average of 11 trials.

Bessel filter (Frequency Devices, Haverhill, MA) and digitized with a 16-bit D/A converter (Instrutech, Great Neck, NY), Pulse Control software (Herrington and Bookman, 1995), and an Apple Macintosh Centris 650 computer. Analysis was done on- and off-line with Igor Pro software (Wavemetrics, Lake Oswego, OR). Exponential fits to facilitation were performed between 10 and $1000 \mathrm{msec}$. The amplitude of facilitation was calculated from this fit for $\Delta t=10 \mathrm{msec}$.

\section{RESULTS}

\section{Facilitation and presynaptic calcium for control conditions}

The synapse between cerebellar granule cells and Purkinje cells exhibits robust paired-pulse facilitation, as shown in Figure 1. Synaptic currents evoked by extracellular stimulation of parallel fibers were measured with whole-cell recordings from the soma of cerebellar Purkinje cells (Perkel et al., 1990; Llano et al., 1991; Mintz et al., 1995). As shown in the inset of Figure 1, stimulation with two pulses separated by $50 \mathrm{msec}$ resulted in a facilitation of $\sim 180 \%$, as calculated by the formula $100 \times(A 2-A 1) / A 1$, where $A 1$ is the amplitude of the unfacilitated synaptic current and $A 2$ is the amplitude of the facilitated current. In Figure 1, the percentage facilitation as a function of interpulse interval $(\Delta t)$ can be approximated by a single exponential decay with an amplitude of $194 \%$ and $\tau=190 \mathrm{msec}$ (solid curve). For a series of such experiments $(n=15)$, the amplitude of facilitation was $153 \pm 11 \%$ (mean \pm SEM), and the time constant of decay was $203 \pm 18 \mathrm{msec}$.

To investigate the role of $[\mathrm{Ca}]_{\text {res }}$ in facilitation, we sought to obtain a measure of $[\mathrm{Ca}]_{\text {res }}$ in parallel fiber presynaptic terminals on the time scale of facilitation, namely in the $1 \mathrm{sec}$ interval after stimulation. Parallel fiber tracts were labeled with calcium indicators as described in Materials and Methods. We have shown previously that indicators with low calcium affinities, such as mag-fura-5 (Claflin et al., 1994) and magnesium green (Zhao et al., 1996), faithfully follow the large and rapid $[\mathrm{Ca}]_{\text {res }}$ transients produced by parallel fiber activation (Regehr and Atluri, 1995; Sabatini and Regehr, 1995). Like many of the other indicators that were developed originally to detect magnesium, these fluorophores have proven to be very useful in detecting large calcium transients without significant interference from magnesium transients (Konishi et al., 1991; Regehr and Atluri, 1995; Zhao et al., 1996). As shown in Figure 2, the time courses of $\Delta F / F$ signals for mag-fura-5 and magnesium green are similar, but fura-2 $\Delta F / F$ transients decay more slowly. The slower $\Delta F / F$ decay with the high-affinity dye fura- 2 is expected for large $[\mathrm{Ca}]_{\text {res }}$ tran-
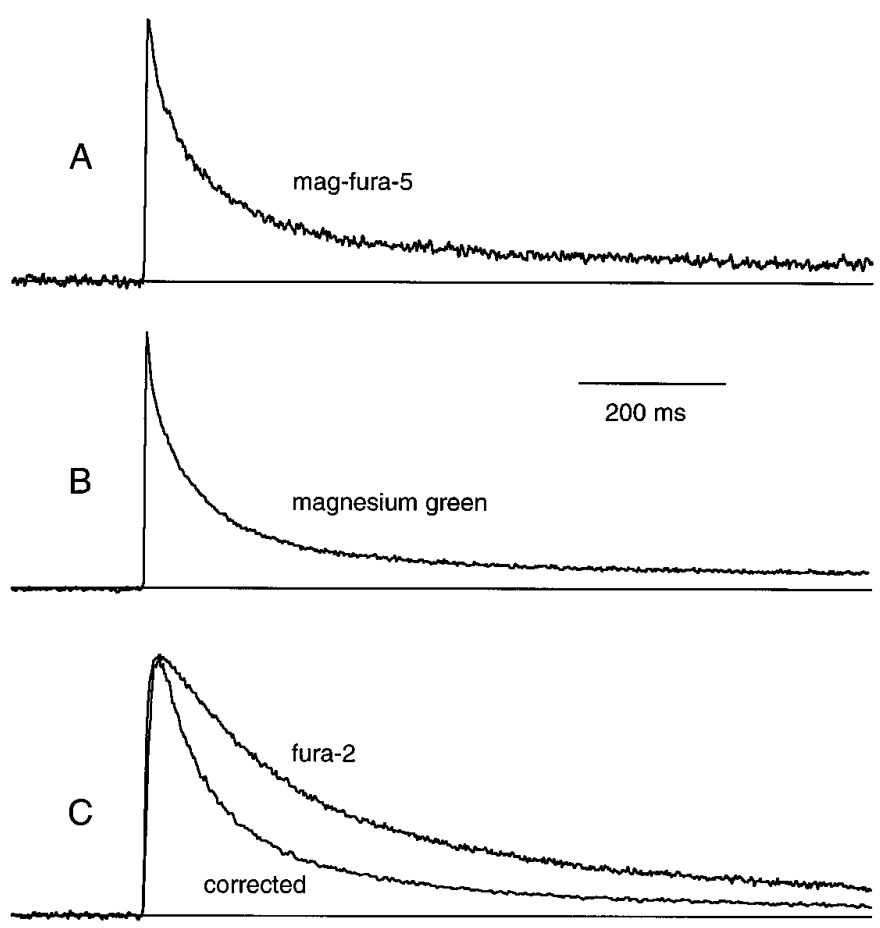

Figure 2. Detection of calcium transients evoked by single stimuli. Time courses of $\Delta F / F$ changes for mag-fura-5 $(A)$, magnesium green $(B)$, and fura-2 $(C)$. The lower trace in $C$ was corrected for distortions, as described in Materials and Methods. Traces are the averages of 8,18 , and 6 experiments, respectively, and were normalized to $(\Delta F / F)_{\text {peak }}$. For the experiments contributing to this figure, the $t_{1 / 2}$ (the time taken for $[\mathrm{Ca}]_{\mathrm{res}}$ to decay from peak levels to $50 \%$ of peak levels) of $\Delta F / F$ changes was $52 \pm$ $2 \mathrm{msec}$ for mag-fura-5, $39 \pm 1 \mathrm{msec}$ for magnesium green, and $181 \pm 32$ msec for fura-2.

sients, which begin to saturate the dye (Regehr and Atluri, 1995; Feller et al., 1996). It is possible, however, to obtain a better estimate of the time course of $[\mathrm{Ca}]_{\text {res }}$ transients by correcting for most of the distortion of fura-2 (see Materials and Methods), as shown in Figure $2 C$. After applying this procedure, the decay of the corrected fura-2 signal resembles more closely those of the low-affinity dyes. For the rest of the studies described here we used magnesium green to detect $[\mathrm{Ca}]_{\text {res }}$. It is less sensitive to calcium $\left(K_{\mathrm{D}} \sim 5 \mu \mathrm{M}\right)$ than is fura- $2\left(K_{\mathrm{D}}\right.$ $\sim 200 \mathrm{~nm}$ ) (Grynkiewicz et al., 1985) but more sensitive than is mag-fura-5 ( $\left.K_{\mathrm{D}} \sim 23 \mu \mathrm{M}\right)$ (Delbono and Stefani, 1993); this allows it to report calcium changes accurately, but with a better signal-to-noise ratio than mag-fura-5.

On the basis of anatomical considerations, such $\Delta F / F$ signals obtained using low-affinity indicators provide a good measure of calcium transients in parallel fiber boutons that synapse onto Purkinje cells, with minimal contamination from other structures. Parallel fibers make a series of en passant synapses as they course through the molecular layer. It is estimated that $\sim 94 \%$ of these synapses are onto Purkinje cell dendrites (Palkovits et al., 1971). Presynaptic contacts are made via closely spaced varicosities, which average $0.8 \mu \mathrm{m}$ in length and $0.18 \mu \mathrm{m}^{3}$ in volume (Palay and Chan-Palay, 1974). They are separated by thin segments of axon $0.15 \mu \mathrm{m}$ in diameter, with an average length of $1.7 \mu \mathrm{m}$ and an average volume of $\sim 0.03 \mu \mathrm{m}^{3}$. We estimate that these presynaptic varicosities comprise $\sim 86 \%$ of the volume of a parallel fiber, with the remainder made up of thin axon.

We also considered the possibility of differential distribution of calcium channels and extrusion mechanisms on the axon 
relative to the presynaptic terminals. If calcium channels and extrusion mechanisms were both located preferentially on axonal segments, then axonal signals could contribute a rapid component to the fluorescence transient, which would make the fluorescence changes we detect difficult to interpret. This is unlikely, because calcium channels and extrusion mechanisms are generally distributed preferentially in presynaptic terminals relative to axons (Cohen et al., 1991; Delaney et al., 1991; Kortje et al., 1991; Luther et al., 1992; Westenbroek et al., 1992, 1995; Smith et al., 1993). This is also true in parallel fibers for the $\alpha_{1 \mathrm{~A}}$ calcium channel subunit (Westenbroek et al., 1995). Thus axonal signals are unlikely to contribute significantly to the fluorescence changes we detect.

To compare the time course of calcium decay to the time course of facilitation, it seemed most natural to compare fits to exponential decays. Fits of the fluorescence transients to single exponential decays provide a crude measure of the decay time of calcium, with a control time constant of $\sim 90 \mathrm{msec}$ over the range $10 \mathrm{msec}$ to $1 \mathrm{sec}$; however, the decay of calcium was not very well approximated by a single exponential, and the decay could not be fit reliably by the sum of two distinct exponentials. Half-decay times $\left(t_{1 / 2}\right)$, the time for $[\mathrm{Ca}]_{\text {res }}$ to decay to $50 \%$ of peak elevation, are useful measures of the decay time of calcium; however, they do not fully describe calcium dynamics and cannot be directly related to time constants of exponential decay. Therefore, to avoid assumptions about the form of the decays, we directly compared the time course of facilitation and residual calcium simply by plotting them on the same graph, as in Figure 3.

After single stimuli, $[\mathrm{Ca}]_{\text {res }}$ decayed more rapidly than did facilitation. Figure $3 A$ shows that at $24^{\circ} \mathrm{C}$ the decay of facilitation, fit by a single exponential with $\tau_{\mathrm{fac}}=184 \mathrm{msec}$ (solid curve), lags behind the decay of $[\mathrm{Ca}]_{\text {res }}$. As shown in Figure $3 B$, raising the temperature to $34^{\circ} \mathrm{C}$ speeds the decay of both facilitation and $[\mathrm{Ca}]_{\text {res }}$, but here too facilitation outlasts the elevation of $[\mathrm{Ca}]_{\text {res }}$. All subsequent experiments were conducted at $24^{\circ} \mathrm{C}$.

These results have important implications for the role of calcium in facilitation. They are inconsistent with the simplest form of the residual calcium hypothesis for paired-pulse facilitation, in which the calcium sensor that triggers release also mediates facilitation. That model predicts that facilitation decays at the same rate as or faster than $[\mathrm{Ca}]_{\text {res. }}$ Instead, we see that calcium decays more rapidly than facilitation.

\section{Altering presynaptic calcium transients with EGTA}

To pursue further the role of $[\mathrm{Ca}]_{\text {res }}$ in paired-pulse facilitation, we decided to manipulate the time course of $[\mathrm{Ca}]_{\text {res }}$ and test its effect on facilitation. As described in Materials and Methods and the Appendix (see Fig. 10), by introducing EGTA into presynaptic boutons we were able to speed the decay of $[\mathrm{Ca}]_{\text {res }}$ (Adler et al., 1991; Winslow et al., 1994; Feller et al., 1996). Because EGTA is a slow calcium chelator, however, it had relatively small effects on the large, brief calcium increases that trigger release.

Figure 4 shows a series of experiments in which successively larger concentrations of EGTA-AM, the membrane-permeant form of EGTA, were bath-applied for $15 \mathrm{~min}$ to parallel fibers. The time courses and amplitudes of $[\mathrm{Ca}]_{\text {res }}$ elevations were monitored with magnesium green (Fig. 4, left panels), with averages of fluorescence transients before and after application of EGTA-AM shown in the right panels; $1 \mu \mathrm{M}$ EGTA-AM accelerated the $t_{1 / 2}$ of $[\mathrm{Ca}]_{\mathrm{res}}$ transients from $36 \mathrm{msec}$ to $16 \mathrm{msec}$ with no significant effect on peak $[\mathrm{Ca}]_{\text {res }}$ levels (Fig. $4 A$ ). Increasing the concentration of presynaptic EGTA with $20 \mu \mathrm{M}$ EGTA-AM led to a more pronounced accelera-
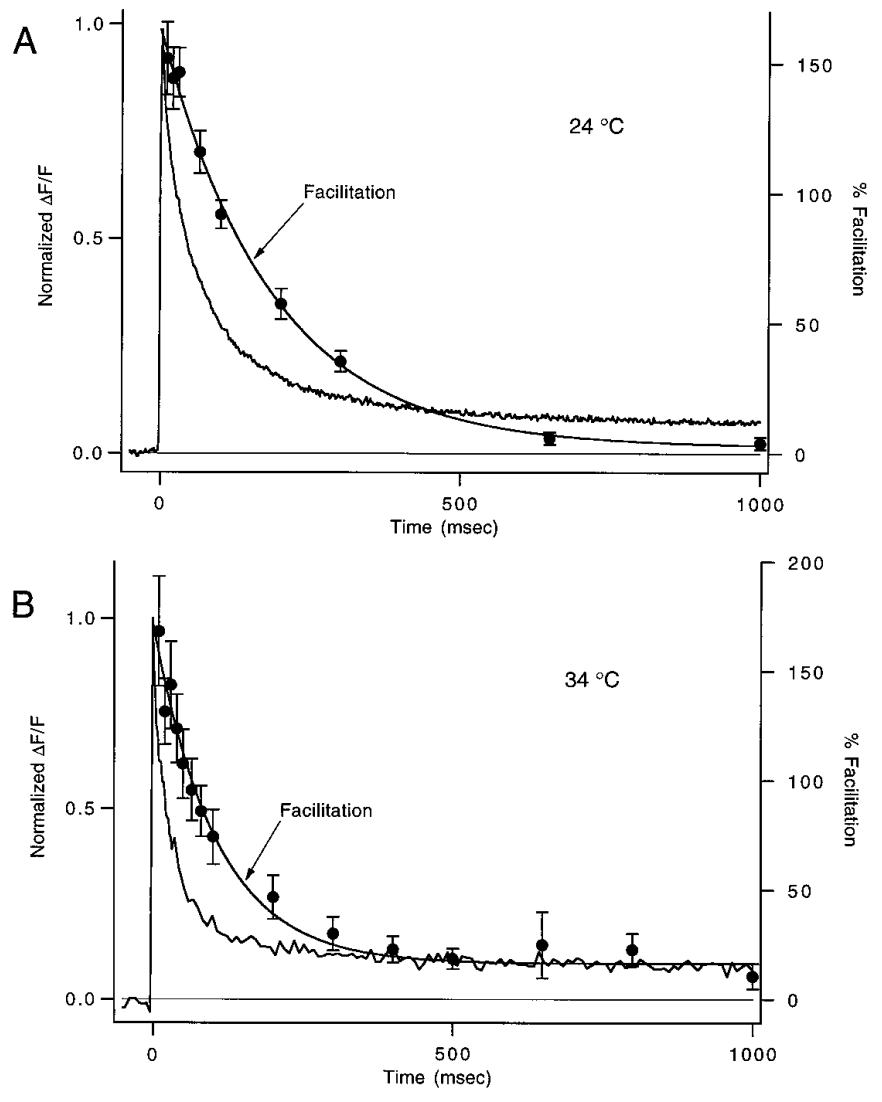

Figure 3. Comparison of the decay times of calcium and facilitation for control conditions. The time courses of synaptic facilitation and normalized $\Delta F / F$ changes produced by single parallel fiber stimulation are shown for $24^{\circ} \mathrm{C}(A)$ and $34^{\circ} \mathrm{C}(B) . \Delta F / F$ traces are averages of 20 experiments at $24^{\circ} \mathrm{C}\left(t_{1 / 2}=39 \pm 1 \mathrm{msec}\right)$ and four experiments at $34^{\circ} \mathrm{C}$ $\left(t_{1 / 2}=20 \pm 2 \mathrm{msec}\right)$. Facilitation points represent the average of 15 experiments at $24^{\circ} \mathrm{C}$ and 10 experiments at $34^{\circ} \mathrm{C}$, and error bars represent SEM. The fits shown are to functions of the form $C_{0}+$ $C_{1} e^{-\left(t / \tau_{\text {fac }}\right)}$. Fit parameters $\left\{C_{0}, C_{1}, \tau_{\text {fac }}\right\}$ were $\{2.4,160,184 \mathrm{msec}\}(A)$ and $\{16.3,156,104 \mathrm{msec}\}(B)$.

tion of the $t_{1 / 2}$ of $[\mathrm{Ca}]_{\text {res }}(32 \mathrm{msec}$ to $6 \mathrm{msec})$, with little if any effect on peak $[\mathrm{Ca}]_{\text {res }}$ levels (Fig. $4 B$ ). Higher concentrations of EGTA-AM (100 $\mu \mathrm{M})$ sped the $t_{1 / 2}$ from $33 \mathrm{msec}$ to $2 \mathrm{msec}$ (Fig. $4 C$ ) and reduced peak $\Delta F / F$ values by $33 \%$.

A summary of the effects of $15 \mathrm{~min}$ applications of EGTA-AM on parallel fiber $[\mathrm{Ca}]_{\text {res }}$ transients is shown in Figure 5 . The $t_{1 / 2}$ for control, $1 \mu \mathrm{M}, 20 \mu \mathrm{M}$, and $100 \mu \mathrm{M}$ were $39 \pm 1 \mathrm{msec}(n=20), 23 \pm$ $2 \mathrm{msec}(n=5), 10 \pm 1 \mathrm{msec}(n=5)$, and $2 \pm 0.2 \mathrm{msec}(n=5)$, respectively; $20 \mu \mathrm{M}$ EGTA-AM caused a small $8 \pm 4 \%$ decrease in peak amplitude, whereas $100 \mu \mathrm{M}$ EGTA-AM decreased peak amplitude by $45 \pm 4 \%$. These experiments demonstrate that EGTA accelerates the decay of $[\mathrm{Ca}]_{\text {res }}$ transients in a dosedependent manner and at higher concentrations begins to attenuate the peak of the $[\mathrm{Ca}]_{\text {res }}$ transient.

\section{Effect of rapid presynaptic calcium dynamics on facilitation}

We then assessed the effect of altered calcium dynamics on facilitation. Parallel fibers were stimulated every $15 \mathrm{sec}$ while the interpulse interval $\Delta t$ was varied and conditioning and test EPSCs were recorded. Figure 6 shows facilitation before and after $15 \mathrm{~min}$ applications of successively higher concentrations of EGTA-AM. A solution of 0 EGTA-AM in $0.1 \%$ DMSO did not significantly 
A
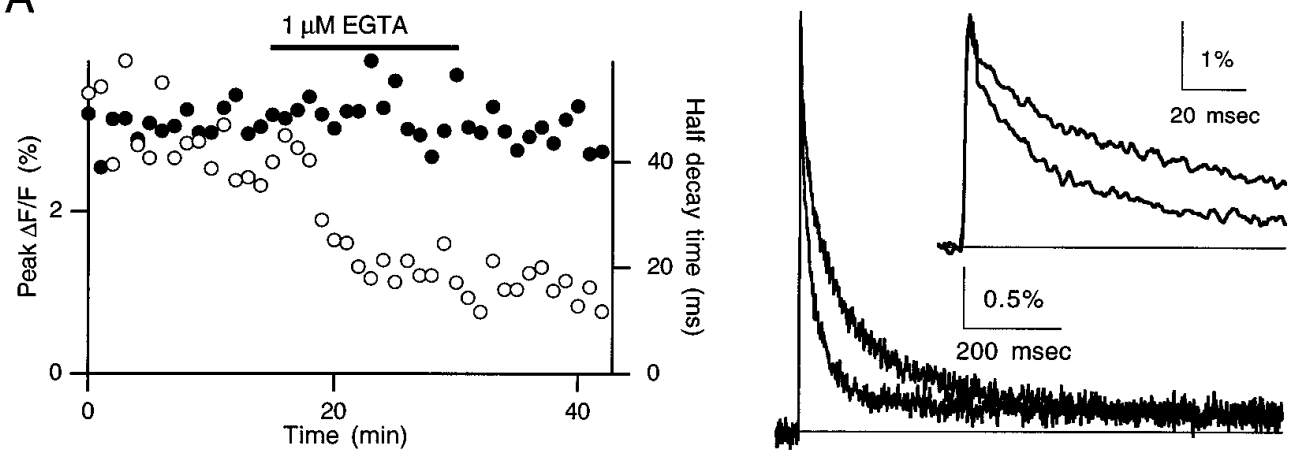

B
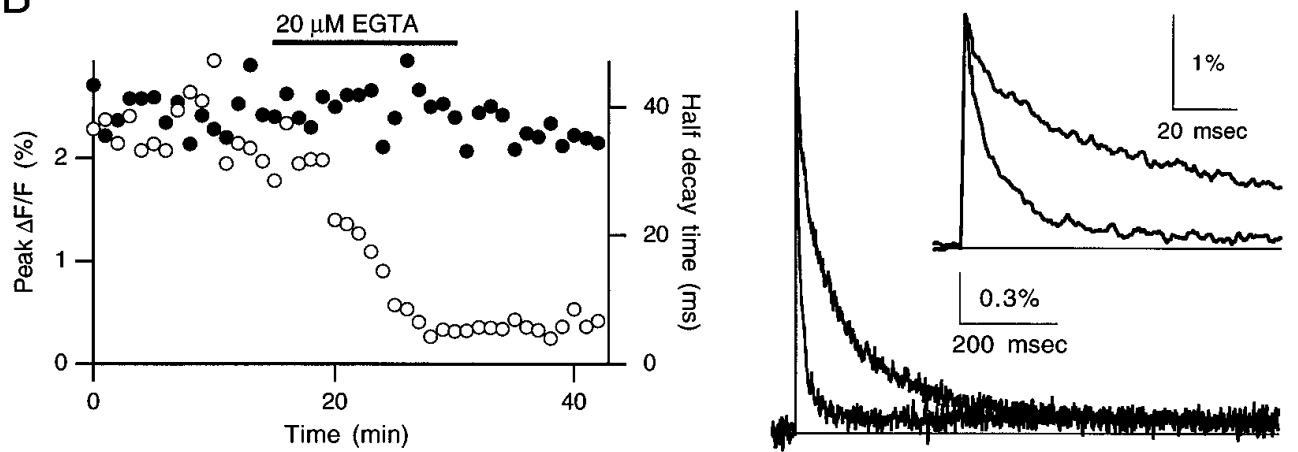

C

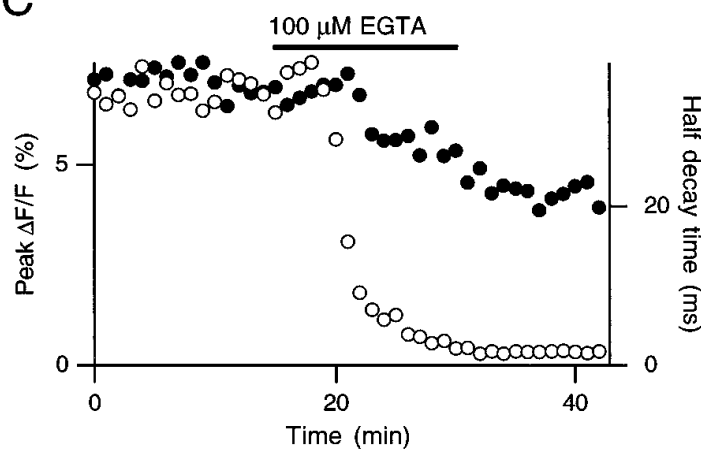

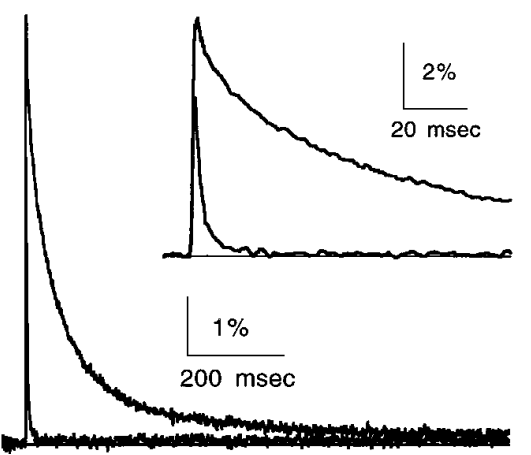

Figure 4. Speeding the decay of calcium with EGTA-AM. The effects of 1 $\mu \mathrm{M}(A), 20 \mu \mathrm{M}(B)$, and $100 \mu \mathrm{M}$ EGTA-AM $(C)$ on the peaks (solid circles) and time constants of decay (open circles) of the stimulus-evoked magnesium green $\Delta F / F$ changes are shown to the left. Corresponding $\Delta F / F$ traces (averages) are shown to the right for control conditions and after the application of EGTA (traces with faster decays). Insets are the same traces shown on an expanded time scale. change the time course of facilitation (Fig. $6 A$ ). Application of 1 $\mu \mathrm{M}$ EGTA-AM accelerated the decay of facilitation without greatly affecting the amplitude of facilitation (Fig. $6 B$ ). Higher concentrations of EGTA-AM had more pronounced effects on the rate of decay of facilitation and also decreased the amplitude of facilitation, as shown in Figure $6 C$ for $20 \mu \mathrm{M}$ EGTA-AM and in Figure $6 D$ for $100 \mu \mathrm{M}$ EGTA-AM.

Although EGTA-AM will load all structures within the slice, including presynaptic terminals and Purkinje cells, it is highly likely that the effect of EGTA-AM on facilitation is a consequence of altered granule cell presynaptic calcium dynamics. Measurements of synaptic currents were made with whole-cell patch pipettes, which dialyzed the contents of the Purkinje cells with 10 mM EGTA; thus, EGTA-AM loading is unlikely to change significantly calcium buffering within recorded Purkinje cells.

Experiments such as those presented in Figure 6 demonstrate the effects of EGTA-AM on recordings from single cells. Because of the length of these experiments $(\geq 1 \mathrm{hr})$, we were unable to avoid small increases in access resistance. To minimize the effects of changes in access resistance, we used very low resistance electrodes (0.9-1.5 M $\Omega$ ) and adjusted the stimulus intensity to keep the amplitudes of unfacilitated EPSCs small. Control experiments on untreated cells recorded for $>1 \mathrm{hr}$ (not shown) showed that the time course of facilitation decay was insensitive to accessresistance changes in this range.

To quantitate better the effect of EGTA-AM on facilitation, we also recorded facilitation curves in cells that had been exposed to EGTA-AM, without measuring the control facilitation curves in the same cells. Such experiments had the advantage that more trials could be performed at a constant series resistance, allowing a better estimate of the time course of facilitation. To overcome cell-to-cell variability, we recorded facilitation curves for many cells, with averages shown in Figure 7. The amplitude of facilitation went from $153 \pm 11 \%(n=15)$ in control conditions to $159 \pm 25 \%(n=14), 74 \pm 8 \%(n=9)$, and $70 \pm 10 \%(n=10)$, respectively, for applications of $1 \mu \mathrm{M}$, $20 \mu \mathrm{M}$, or $100 \mu \mathrm{M}$ EGTA-AM. As is seen most clearly in Figure $7 B$, the time constant of decay of facilitation was also affected, declining from a control value of $203 \pm 18 \mathrm{msec}$ to $138 \pm 19$ 


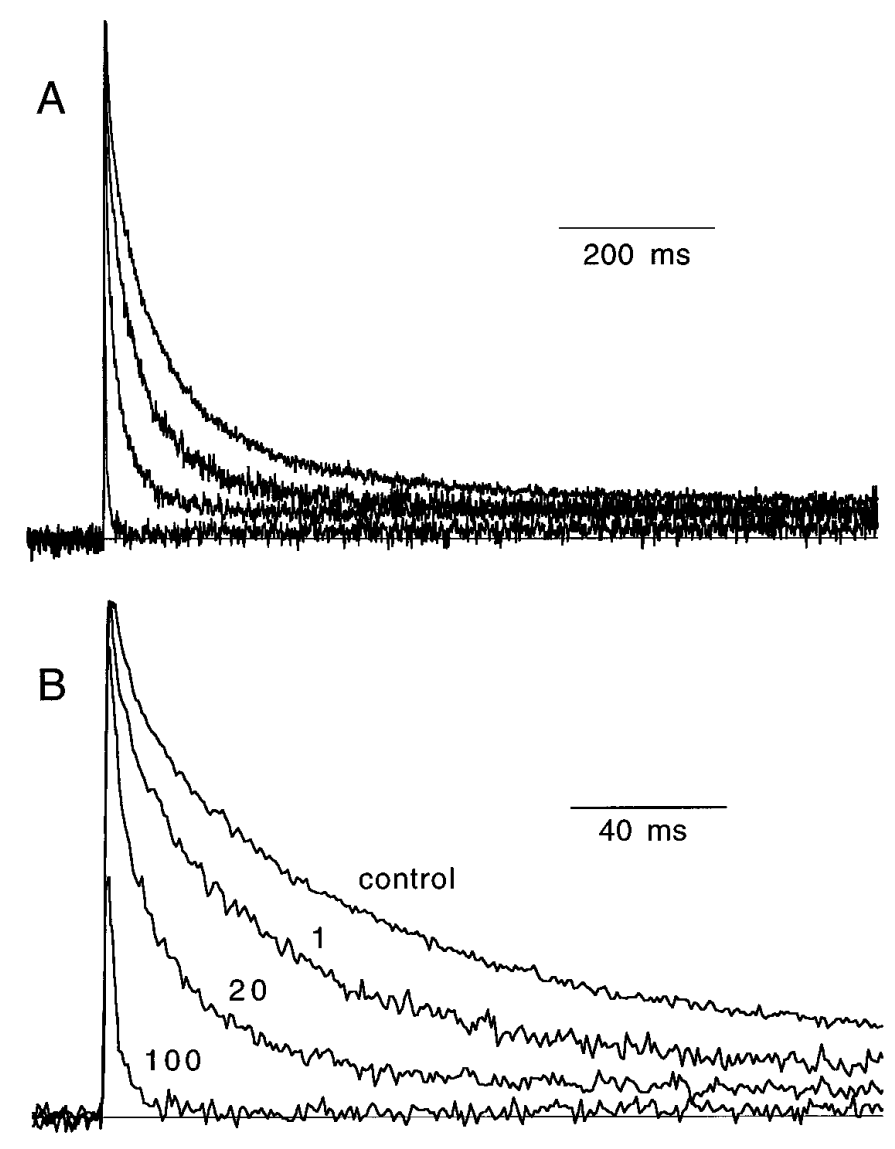

Figure 5. Summary of the effect of EGTA loading on calcium transients. $\Delta F / F$ changes detected with magnesium green produced by a single stimulus of the parallel fibers for control and 1, 20, and $100 \mu \mathrm{M}$ EGTA-AM on long $(A)$ and short $(B)$ time scales. Traces are averages from 20,5, 5, and 5 experiments, respectively. Before averaging, each post-treatment trace was normalized to the pretreatment peak fluorescence.

msec, $85 \pm 11 \mathrm{msec}$, and $52 \pm 4 \mathrm{msec}$ for $1 \mu \mathrm{M}, 20 \mu \mathrm{M}$, or 100 $\mu \mathrm{M}$ EGTA-AM, respectively.

Figure 8 compares the time course of $[\mathrm{Ca}]_{\mathrm{res}}$ transients with the time course of facilitation for control conditions and after altering $[\mathrm{Ca}]_{\text {res }}$ dynamics. For all of our experimental conditions, $[\mathrm{Ca}]_{\text {res }}$ decayed more rapidly than did facilitation (Fig. $8 A$ ). As shown in Figure $8 B$, increasing the decay rate of $[\mathrm{Ca}]_{\text {res }}$ in turn speeds the decay of facilitation.

\section{Simulations of calcium-activated facilitation}

In considering the mechanisms underlying facilitation, we explored the following general reaction scheme, in which calcium binds to a receptor, $\mathrm{X}$, to produce $\mathrm{CaX}$, whose concentration is directly proportional to facilitation, where $k^{+}$and $k^{-}$are the forward and reverse rate constants:

$$
\mathrm{Ca}+\mathrm{X} \underset{k^{-}}{\stackrel{k^{+}}{\rightleftharpoons}} \mathrm{CaX} .
$$

The relationship between $[\mathrm{Ca}]_{\text {res }}$ and facilitation could be accounted for by a simple model (Fig. 9, solid traces) that assumes facilitation is the result of a second-order calcium-dependent reaction with one-to-one binding, a $k^{+}$of $1.5 \times 10^{8} \mathrm{M}^{-1} \mathrm{sec}^{-1}$, and an effective $k^{-}$of $25 \mathrm{sec}^{-1}$, corresponding to a dissociation constant of $167 \mathrm{~nm}$.
The purpose of these simulations was to examine the feasibility of the involvement in facilitation of a high-affinity calcium binding site, and to test the range of parameters that adequately relate the observed calcium transients and facilitation. The strategy was to impose a $[\mathrm{Ca}]_{\text {res }}$ transient with an amplitude of $200 \mathrm{~nm}$ for control conditions (as estimated previously) (Regehr and Atluri, 1995), and a time course determined experimentally, as shown in Figure 5. We then tried to approximate the experimental facilitation curves by varying $k^{+}$and $k^{-} . k^{-}$was estimated from the facilitation observed after exposure to $100 \mu \mathrm{M}$ EGTA-AM as $k^{-} \approx\left(\tau_{\text {fac }}\right)^{-1}$, which is $\sim 25$ $\sec ^{-1}$. We then tried various values of $k^{+}$and found that none of them were consistent with the data. To see why no value of $k^{+}$ proved to be satisfactory, consider the two constraints that had to be satisfied simultaneously. First, facilitation is observed to peak $<20$ msec after the conditioning pulse. For a model of this sort, the rise time of facilitation can be approximated by $\tau_{\text {rise }}=\left(k^{+}[\mathrm{Ca}]+k^{-}\right)^{-1}$. For $k^{-}=25 \mathrm{sec}^{-1}$ and [Ca] $=200 \mathrm{nM}, k^{+}$must be $>4 \times 10^{8} \mathrm{M}^{-1}$ $\mathrm{sec}^{-1}$. On the other hand, $K_{\mathrm{D}}$ must be $>150 \mathrm{~nm}$ to be consistent with the observed amplitudes of facilitation. Because $K_{\mathrm{D}}=k^{-} / k^{+}, k^{+}$ must be $<2 \times 10^{8} \mathrm{M}^{-1} \mathrm{sec}^{-1}$, a conclusion inconsistent with the constraint imposed by the rapid rise of facilitation. Another complication is that the extremely brief and rather small calcium signals observed for $100 \mu \mathrm{M}$ EGTA-AM experiments are predicted to produce much less facilitation than the larger, longer-lasting calcium signals of the $20 \mu \mathrm{M}$ EGTA-AM experiments, yet this is not observed.

Considerations of models of calcium transients within cells suggested a likely explanation for the inadequacies of the simulations described above. In models that take into account the spatial gradients of calcium on rapid time scales, it is apparent that calcium levels can be extremely high near open calcium channels (Simon and Llinas, 1985; Augustine and Neher, 1992; Yamada and Zucker, 1992). Fluorometric measurements such as those used here, however, are not very sensitive to the high local calcium transients near open calcium channels. It seemed to us that the most straightforward explanation of our results is that in addition to the calcium transients we can measure, there is a brief pulse of calcium that produces some facilitation by binding to its receptor $\mathrm{X}$, but which we are unable to detect. The amplitude of the calcium pulse will depend on the location of $X$ relative to the open calcium channels. Very near calcium channels this value could approach $100 \mu \mathrm{M}$ (Roberts et al., 1990), but at more distant sites this value will be lower. Because we do not know the location of $\mathrm{X}$, we fixed the duration of this pulse at $1 \mathrm{msec}$ and varied its amplitude. This approach provided a good approximation to the observed facilitation for various different presynaptic calcium transients, as shown in Figure 9. These simulations used a $1.5 \mu \mathrm{M}$ calcium pulse of $1 \mathrm{msec}$ duration combined with calcium transients with time courses and relative amplitudes determined on the basis of Figure 5. This second component increased $[\mathrm{Ca}]_{\text {res }}$ by $200 \mathrm{~nm}$ for control traces.

\section{DISCUSSION}

\section{Facilitation at the granule cell $\rightarrow$ Purkinje cell synapse involves a high-affinity calcium binding site with slow effective kinetics}

Our experiments indicate that $[\mathrm{Ca}]_{\text {res }}$ plays an important role in facilitation. Speeding the decay of $[\mathrm{Ca}]_{\text {res }}$ levels with EGTA-AM (Figs. 4, 5) accelerated the decay of facilitation (Figs. 6, 7) in a dose-dependent manner. The application of $1 \mu \mathrm{M}$ EGTA-AM increased the decay rate of both $[\mathrm{Ca}]_{\text {res }}$ and facilitation without affecting their peak levels. Higher concentrations of EGTA-AM 

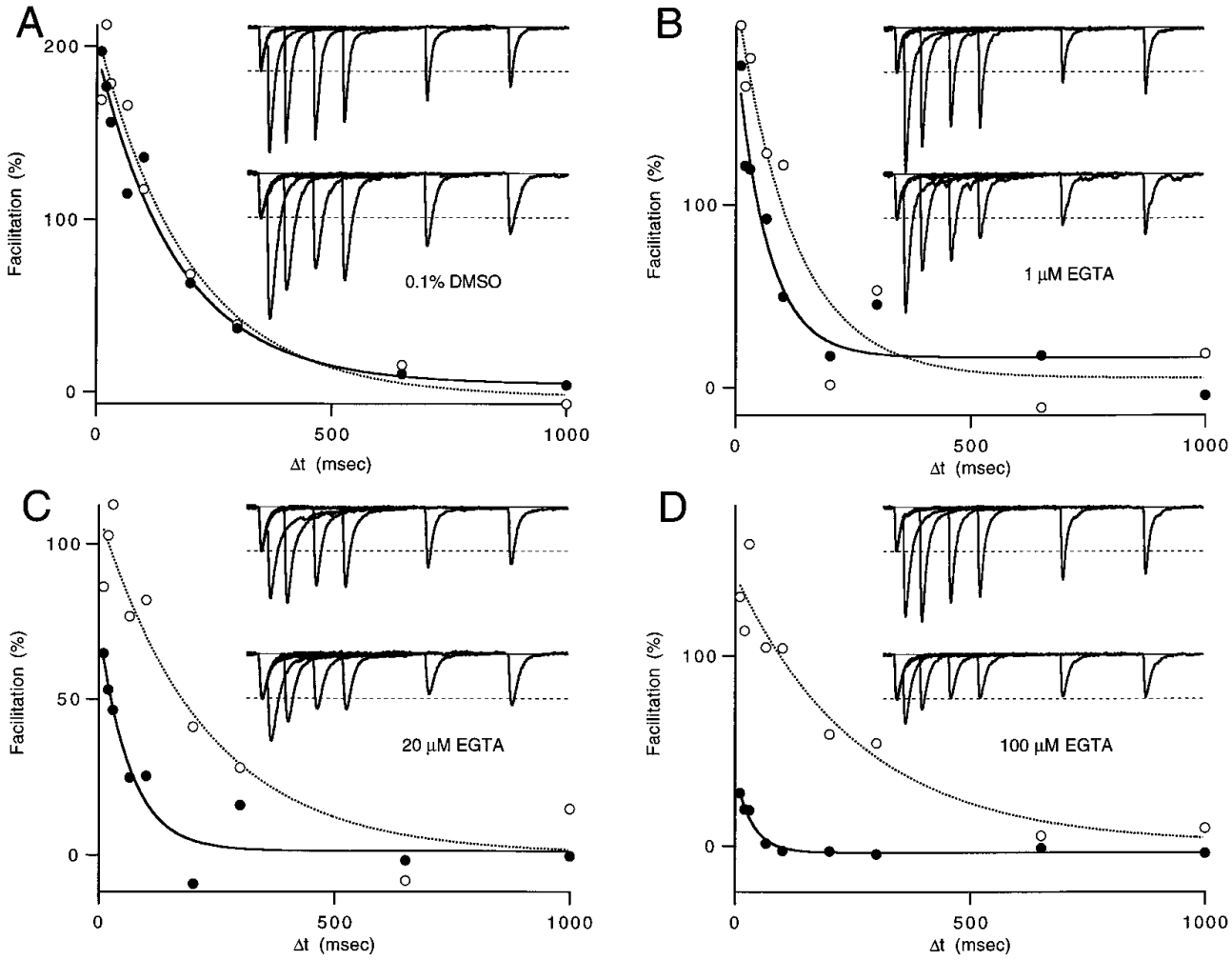

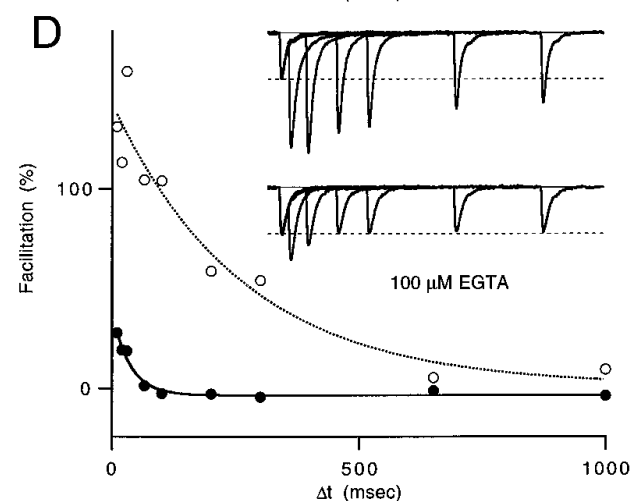

Figure 6. Altering calcium dynamics changes the time course of facilitation. Facilitation before (open circles) and after (solid circles) 15 min applications of $0.1 \%$ DMSO and 0 EGTA-AM $(A), 1 \mu \mathrm{M}$ EGTA-AM $(B), 20 \mu \mathrm{M}$ EGTA-AM $(C)$, and $100 \mu \mathrm{M}$ EGTA-AM $(D)$. Each point is the mean of two to four trials. The fits shown are to functions of the form $C_{0}+$ $C_{1} e^{-\left(t / \tau_{\mathrm{fac}}\right)}$, with dashed and solid lines corresponding to open and solid circles, respectively. Before and after fit parameters $\left\{C_{0}, C_{1}, \tau_{\text {fac }}\right\}$ were $\{-3,211,199\},\{4,192$, 174\} $(A) ;\{5,207,124\},\{17,167,67\}(B)$; $\{1,109,224\},\{1,72,65\}(C)$; and $\{1,142$, $263\},\{-3,42,36\}(D)$. Each inset shows six superimposed average traces of conditioning and test EPSCs $(\Delta t=10,30,65$, 100,200 , and $300 \mathrm{msec}$ ) obtained from a single Purkinje cell before (top) and after (bottom) application of the indicated solutions. In these experiments, the amplitudes (pA) of conditioning EPSCs before and after EGTA-AM application were 283 and $107(A), 326$ and $147(B), 262$ and $142(C)$, and 348 and $203(D)$. The reduction in amplitude observed in these long experiments was gradual, suggesting that it was not a product of either the DMSO or the EGTA-AM treatment.
$(20 \mu \mathrm{M})$ also left peak $[\mathrm{Ca}]_{\text {res }}$ largely unaffected, whereas they further accelerated the decay of $[\mathrm{Ca}]_{\text {res }}$. For these conditions the peak amplitude and duration of facilitation both decreased. We have shown previously that a single stimulus results in a peak increase in $[\mathrm{Ca}]_{\mathrm{res}}$ of 200-300 nM (Regehr and Atluri, 1995). These results indicate that the processes responsible for facilitation are sensitive to the small elevations in $[\mathrm{Ca}]_{\text {res }}$ (tens to hundreds of nanomolar) remaining in these terminals in the first second after action-potential invasion, which supports the existence of a high-affinity calcium receptor whose occupancy is related to maintenance of facilitation.

There is also a component of facilitation that persists after $[\mathrm{Ca}]_{\text {res }}$ has returned to resting levels. This is most apparent after treating presynaptic terminals with high $(100 \mu \mathrm{M})$ concentrations of EGTA-AM, which speeds the decay of $[\mathrm{Ca}]_{\text {res }}$ to such an extent that it becomes a brief impulse lasting only a few milliseconds. Facilitation is still present for such conditions, and persists for tens of milliseconds after a conditioning pulse.

Taken together, our results establish that the time course of facilitation is set in part by the decay of $[\mathrm{Ca}]_{\mathrm{res}}$ and in part by the slow kinetics of either calcium binding or of the calcium-activated process that produces facilitation.

\section{Simulations of facilitation}

The simulations of facilitation (Fig. 9) demonstrate that a model for facilitation based on a calcium-driven reaction with secondorder kinetics provides an adequate description of facilitation at this synapse. One particularly interesting aspect of these simulations is that it is possible to think in terms of two components of facilitation, one driven by residual calcium and another driven by locally high levels of calcium that our calcium measurement techniques cannot detect (see Materials and Methods). Facilitation curves in conditions in which residual calcium decays extremely rapidly (Fig. $8 A)(100 \mu \mathrm{M}$ EGTA-AM experiments) allow us to estimate the intrinsic time constant of facilitation for our experimental conditions to be $\sim 40 \mathrm{msec}$. According to reaction scheme (3) above, this intrinsic time constant reflects the reverse rate constant of calcium binding, which is given by $\left(\tau_{\text {fac }}\right)^{-1}=25$ $\mathrm{sec}^{-1}$. According to this model, facilitation at this synapse involves a site with rapid forward kinetics $\left(1.5 \times 10^{8} \mathrm{M}^{-1} \mathrm{sec}^{-1}\right)$ but with a high affinity for calcium $\left(K_{\mathrm{D}}=167 \mathrm{~nm}\right)$.

In this model, facilitation decay lags behind $[\mathrm{Ca}]_{\mathrm{res}}$ decay for two reasons. The first reason is the slow kinetics of calcium dissociation, which determines the time course of facilitation when residual calcium decays very rapidly. The second reason to expect facilitation to lag behind $\mathrm{Ca}$ is saturation of its receptor $\mathrm{X}$, which significantly slows the decay of facilitation in control conditions. When $\mathrm{X}$ is nearly saturated, an increase in $[\mathrm{Ca}]_{\text {res }}$ produces a very small increase in [CaX]. Conversely, for a given decrease in $[\mathrm{Ca}]_{\text {res, }}$, a much smaller decrease in $[\mathrm{CaX}]$ occurs if $\mathrm{X}$ is nearly saturated than would occur if $\mathrm{X}$ were far from saturation. If the $K_{\mathrm{D}}$ of $\mathrm{X}$ is comparable in magnitude to the $200-300 \mathrm{~nm} \mathrm{Ca}$ elevations produced in these terminals by single action potentials, then the saturation of $\mathrm{X}$ may contribute to the observed differences between the time course of facilitation and that of $[\mathrm{Ca}]_{\text {res }}$ transients. In this model, the slow decay of facilitation owing to saturation of $\mathrm{X}$ is analogous to the slow decay of the fluorescence transients reported by high-affinity dyes such as fura-2 (Fig. $2 C$ and Materials and Methods) (Regehr and Atluri, 1995).

According to the model presented at the end of the Results section, there is significant calcium binding to the receptor $\mathrm{X}$ even at resting calcium levels, because the $K_{\mathrm{D}}$ for the calcium binding site is just $167 \mathrm{~nm}$. In the simulations of Figure 9, which assumed a resting calcium of $40 \mathrm{nM},[\mathrm{CaX}] /\left[\mathrm{X}_{\text {total }}\right]$ went from 0.19 to 0.48 , an increase of $150 \%$. The amplitude of this increase is about the same as the magnitude of facilitation for these conditions, suggesting that unfacilitated release may also depend on calcium binding to $\mathrm{X}$. 

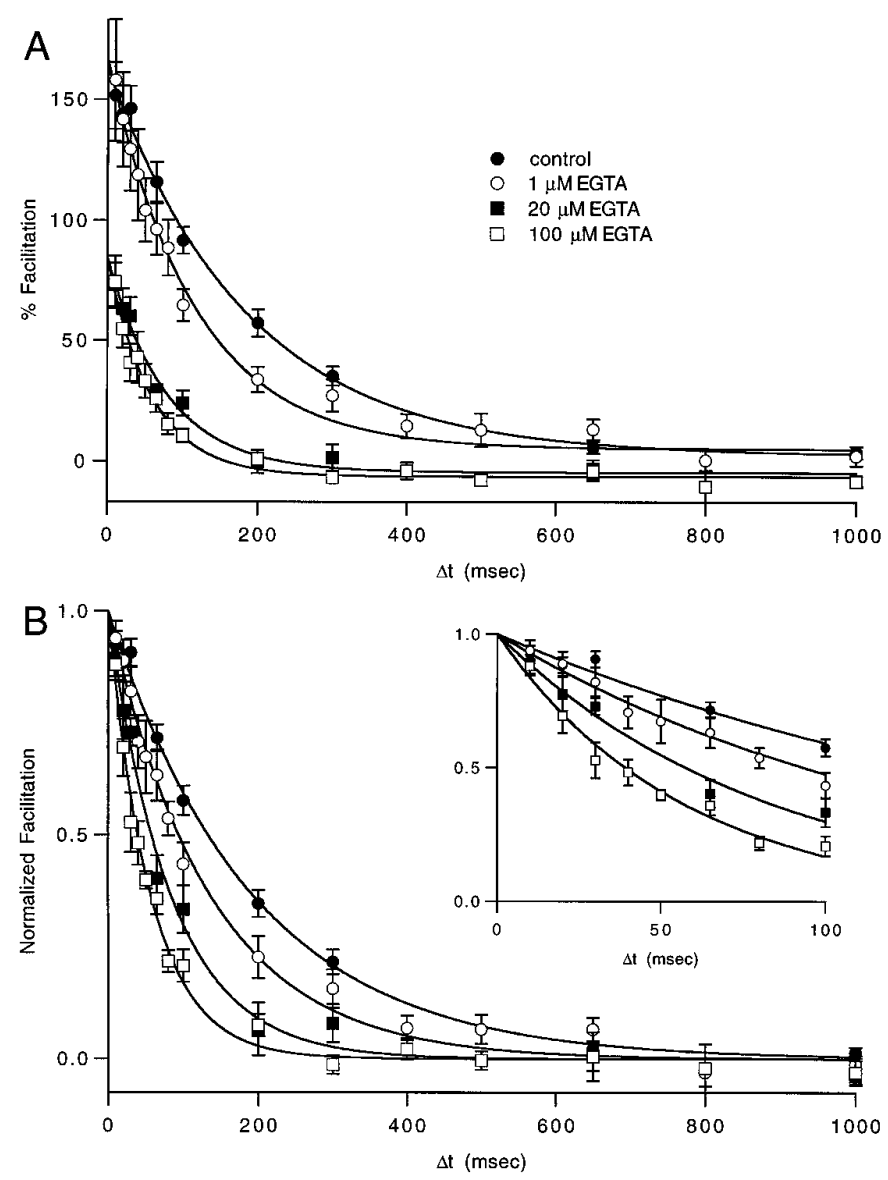

Figure 7. Summary of the effect of EGTA-loading on facilitation. Averages of non-normalized $(A)$ and normalized $(B)$ facilitation in control solution and after treatment with 1,20 , or $100 \mu \mathrm{M}$ EGTA-AM. For normalized curves, the facilitation curves from each cell were fit with a single exponential (which was not constrained to decay to 0 ), normalized to decay from 1 to 0 , and then averaged with the other cells. Inset in $B$ shows the same curves on an expanded time scale. Fit parameters for control, 1, 20, and $100 \mu \mathrm{M}$ EGTA-AM in $A$ were $\{2,160,184\},\{5,162$, $114\},\{-5,89,78\}$, and $\{-6,90,59\} . \tau_{\text {decay }}$ for curves in $B$ were 203,138 , 85 , and $52 \mathrm{msec}$, respectively.

It must be stressed that the working model based on a calciumdriven reaction with simple kinetics (Fig. 9) is still preliminary and that additional experiments will be required to unravel some of the details of the role of calcium in facilitation. One deficiency of the model is that for control conditions elevations of $[\mathrm{Ca}]_{\mathrm{res}}$ seem to outlive facilitation (Fig. $3 A$ for interpulse intervals $>500 \mathrm{msec}$ ). This may reflect small contributions of additional processes, such as depression, to use-dependent changes in synaptic strength. In addition, other models, which are slightly more complex, can also describe our data. For example, consider the following general reaction scheme, in which calcium first binds to its receptor $\mathrm{X}$ to produce $\mathrm{CaX}$, which then undergoes an activation reaction to produce $\mathrm{CaX}^{*}$, a species directly proportional to facilitation:

$$
\mathrm{Ca}+\mathrm{X} \underset{k_{1}^{-}}{\stackrel{k_{1}^{+}}{\rightleftharpoons}} \mathrm{CaX} \underset{k_{2}^{-}}{\stackrel{k_{2}^{+}}{\rightleftharpoons}} \mathrm{CaX}^{*},
$$

where $k_{1}^{+}, k_{1}^{-}, k_{2}^{+}$, and $k_{2}^{-}$are forward and backward rate constants for steps 1 and 2, respectively. According to this model, when $[\mathrm{Ca}]_{\text {res }}$ decay has been greatly accelerated by $100 \mu \mathrm{M}$

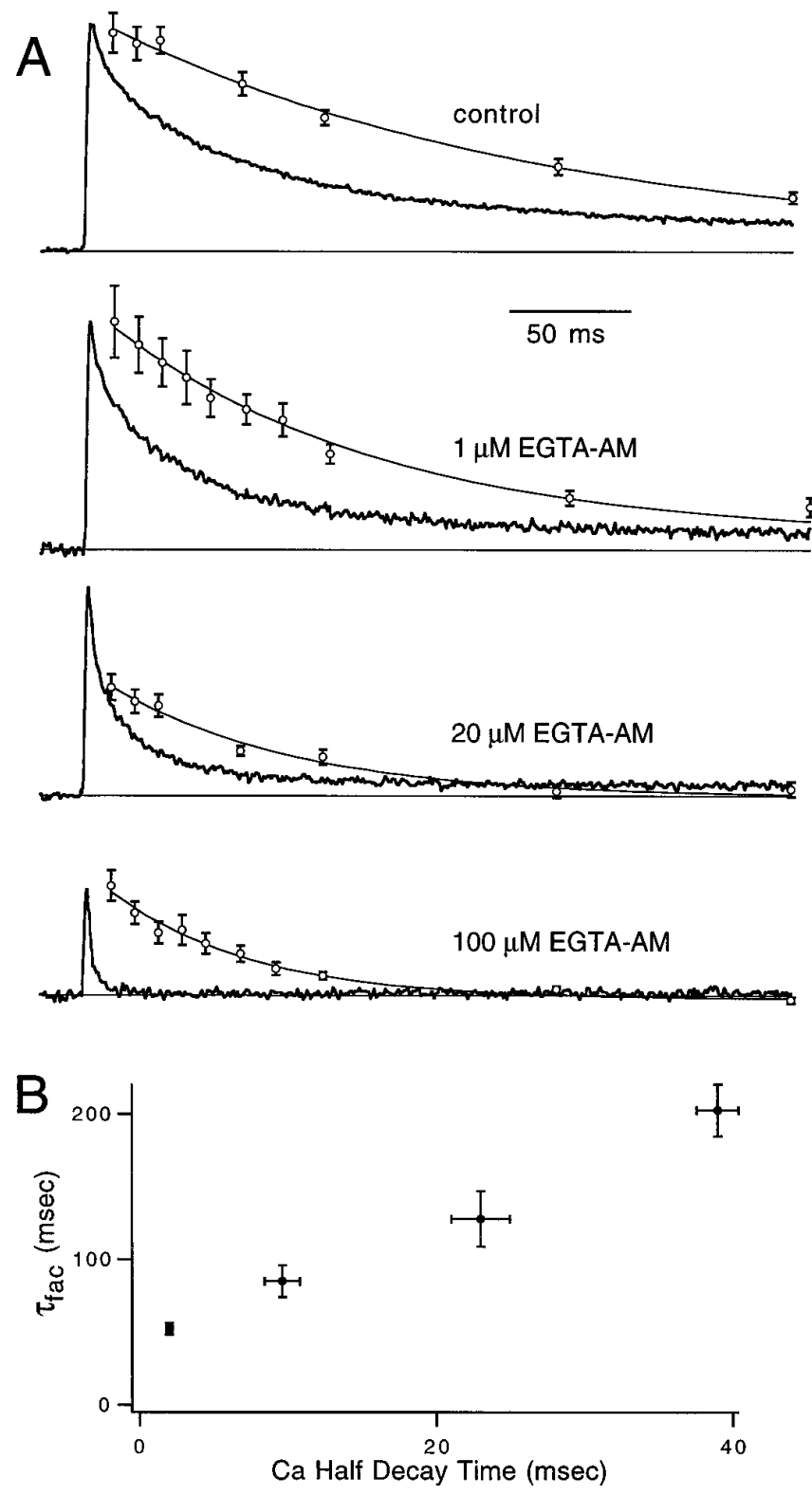

Figure 8. Comparison of calcium transients and facilitation. A, Time course of calcium transients (solid traces) and facilitation (open circles) for control conditions and after altering calcium dynamics with $15 \mathrm{~min}$ applications of 1,20 , and $100 \mu \mathrm{M}$ EGTA-AM. Both calcium transients and facilitation from EGTA-AM experiments have been normalized to peaks from control conditions. Smooth curves are fits to the average facilitation. $B$, The time constant of decay of facilitation is plotted as a function of the $t_{1 / 2}$ of calcium decay. Each point is the average \pm SEM determined from $15,14,9$, and 10 experiments, respectively, for facilitation, and 20,5, 5, and 5 experiments for calcium.

EGTA-AM treatment, the duration of facilitation could be dominated by either the kinetics of calcium dissociation, $k_{1}^{-}$, or the kinetics of $\mathrm{CaX}^{*}$ returning to $\mathrm{CaX}, k_{2}^{-}$.

\section{Comparison to other synapses}

It is instructive to compare the role of $[\mathrm{Ca}]_{\text {res }}$ in facilitation at the granule cell to Purkinje cell synapse with that described previously at other synapses. It seems that a high-affinity calcium-binding site distinct from that involved in triggering release is involved in facilitation for the crayfish NMJ and frog tectal synapses (Yamada 


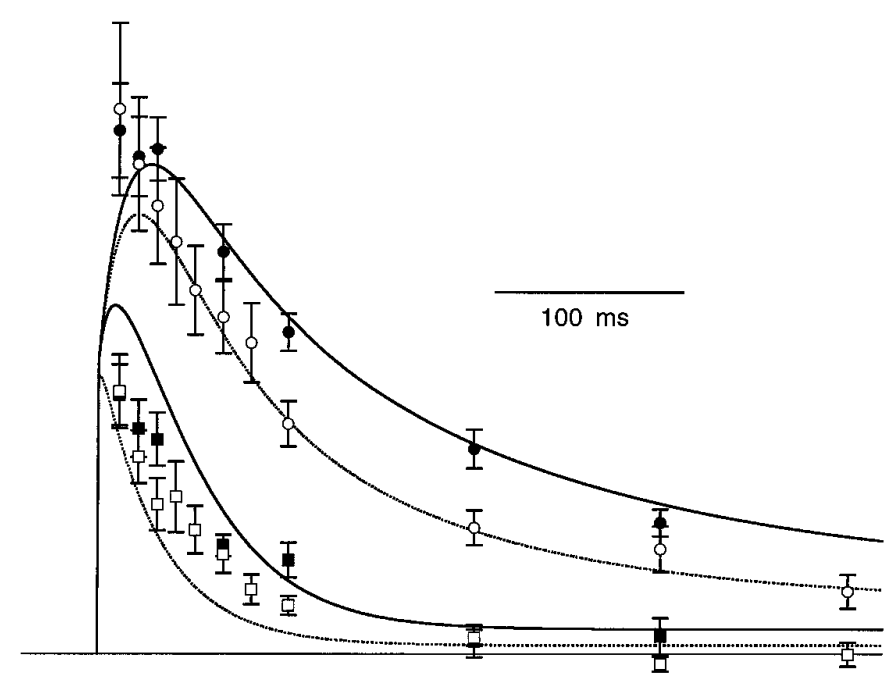

Figure 9. Comparison of experimental and simulated facilitation. Experimentally determined and simulated time courses of facilitation for control conditions (solid circles, solid line) and after altering calcium dynamics with 15 min applications of $1 \mu \mathrm{M}$ EGTA-AM (open circles, dotted line), $20 \mu \mathrm{M}$ EGTA-AM (solid squares, solid line), and $100 \mu \mathrm{M}$ EGTA-AM (open squares, dotted line). The simulations used the following properties for the facilitating molecule: $k^{-}=25 \mathrm{sec}^{-1}$ and $k^{+}=$ $1.5 \times 10^{8} \mathrm{M}^{-1} \mathrm{sec}^{-1}$, corresponding to $K_{\mathrm{D}}$ of $167 \mathrm{nM}$. Resting calcium was taken to be $40 \mathrm{nM}$, which corresponded to $[\mathrm{CaX}] /\left[\mathrm{X}_{\text {total }}\right]=0.19$ at rest. For control simulations, peak $[\mathrm{CaX}] /\left[\mathrm{X}_{\text {total }}\right]=0.48$.

and Zucker, 1992; Blundon et al., 1993; Delaney and Tank, 1994; Winslow et al., 1994). As we have shown here, this is true also for a synapse in mammalian brain, suggesting that this may be a universal feature of facilitation that extends from invertebrates to mammals. Similarly, delayed release of neurotransmitter, a process long thought to be closely related to facilitation, may involve a high-affinity calcium binding site (Goda and Stevens, 1994).

Important features of facilitation, however, are not universal. The relative importance of calcium dynamics and the kinetics of the calcium-activated process in determining the time course of facilitation depend on the unique properties of a synapse. In one extreme, calcium-activated reaction kinetics dictate the time course of facilitation when they are much slower than calcium dynamics. This is consistent with the conclusion that $[\mathrm{Ca}]_{\text {res }}$ dynamics does not play a prominent role in determining the time course of facilitation at the crayfish NMJ (Blundon et al., 1993; Delaney and Tank, 1994; Winslow et al., 1994) and at frog tectal synapses (Feller et al., 1996). This also seems to hold in our experiments when $100 \mu \mathrm{M}$ EGTA-AM has been used to speed the decay of $[\mathrm{Ca}]_{\text {res }}$. Conversely, calcium dynamics much slower than the effective reaction kinetics would dictate the time course of facilitation, as suggested by experiments with caged calcium chelators (Kamiya and Zucker, 1994). More generally, both calcium dynamics and effective reaction kinetics combine to determine the time course of facilitation, as is apparent here for the granule cell to Purkinje cell synapse.

Our results differ greatly from the only other direct examination of calcium dynamics and facilitation in mammalian brain of which we are aware (Wu and Saggau, 1994). They reported that at the hippocampal CA3-CA1 synapse, $[\mathrm{Ca}]_{\text {res }}$ and facilitation have the same decay rate, suggesting that the time course of facilitation closely follows the $[\mathrm{Ca}]_{\text {res }}$ time course. They also reported that the calcium influx evoked by the second of two closely spaced stimuli is reduced in amplitude, suggesting the paradoxical result that facilitation occurs when there is less calcium entering to trigger release. Interpretation of their experiments may have been confounded, however, by their use of a high-affinity dye to measure $[\mathrm{Ca}]_{\text {res }}$. In preliminary studies of $[\mathrm{Ca}]_{\text {res }}$ at the CA3-CA1 synapse using low- and high-affinity fluorescent calcium indicators, we found that fura- 2 begins to saturate and overestimates the decay time of $[\mathrm{Ca}]_{\text {res }}$ (W. Regehr, unpublished observations) (Fig. 2). We conclude that $[\mathrm{Ca}]_{\text {res }}$ decays more rapidly than facilitation at the CA3-CA1 synapse, much as shown here for the granule cell to Purkinje cell synapse. It seems likely, therefore, that $[\mathrm{Ca}]_{\text {res }}$ also plays a similar role in facilitation at both synapses. Furthermore, we have found that the calcium influx evoked by the second of two closely spaced stimuli remains constant, both in granule cell presynaptic terminals (Regehr and Atluri, 1995) and in CA3 pyramidal cell presynaptic terminals.

\section{Comparison to the role of calcium in augmentation and PTP}

The role of $[\mathrm{Ca}]_{\text {res }}$ in facilitation as described here is reminiscent of that proposed for $[\mathrm{Ca}]_{\text {res }}$ in augmentation and PTP. These forms of use-dependent synaptic enhancement, which last for tens of seconds, are observed during and after periods of elevated firing that increase $[\mathrm{Ca}]_{\text {res }}$. In augmentation and PTP, modest elevations of $[\mathrm{Ca}]_{\text {res }}$ (tens to hundreds of nanomolar) enhance release by binding to high-affinity sites (Delaney et al., 1989; Swandulla et al., 1991; Delaney and Tank, 1994; Kamiya and Zucker, 1994; Regehr and Mintz, 1994). It seems that facilitation, augmentation, and PTP all involve calcium-activated processes with effective affinities and kinetics suited to their task.

Here we have used a stimulus protocol that emphasizes a rapidly decaying form of enhancement. With longer stimulus trains, additional forms of use-dependent plasticity such as PTP are also present at this synapse, but as yet the details of the action of calcium in such processes have not been described.

\section{Implications for the properties of molecules involved in facilitation}

Our findings constrain the properties of the molecule or molecules that govern the time course of facilitation at the granule cell to Purkinje cell synapse. The calcium sensor for facilitation must have a high calcium affinity and must be activated rapidly (i.e., have a fast on-rate). Furthermore, the molecular mechanism responsible for facilitation introduces a delay between calcium and facilitation, either through slow kinetics of calcium binding or of a long-lived product of a calcium-driven reaction. Calmodulin and synaptotagmin III, both of which are present in parallel fibers and sensitive to moderate levels of calcium (Ullrich et al., 1994; Li et al., 1995), are candidate calcium sensors involved in facilitation (Llinas et al., 1991; Rosahl et al., 1995; Schweizer et al., 1995; Sudhof, 1995). A comparison of the kinetics of calcium-triggered processes involving such proteins with the kinetics observed here at the granule cell to Purkinje cell synapse would help to identify the molecules underlying paired-pulse facilitation.

\section{APPENDIX}

\section{Simulations of the effect of EGTA on calcium transients}

We sped the decay of $[\mathrm{Ca}]_{\text {res }}$ by introducing EGTA to presynaptic terminals (Figs. 4-8). Bath-applied EGTA-AM, a membranepermeant form of the chelator, freely entered cells, where it was deesterified and rendered cell-impermeant, and accumulated within parallel fibers (Tsien, 1981). In this way, achieved levels of 

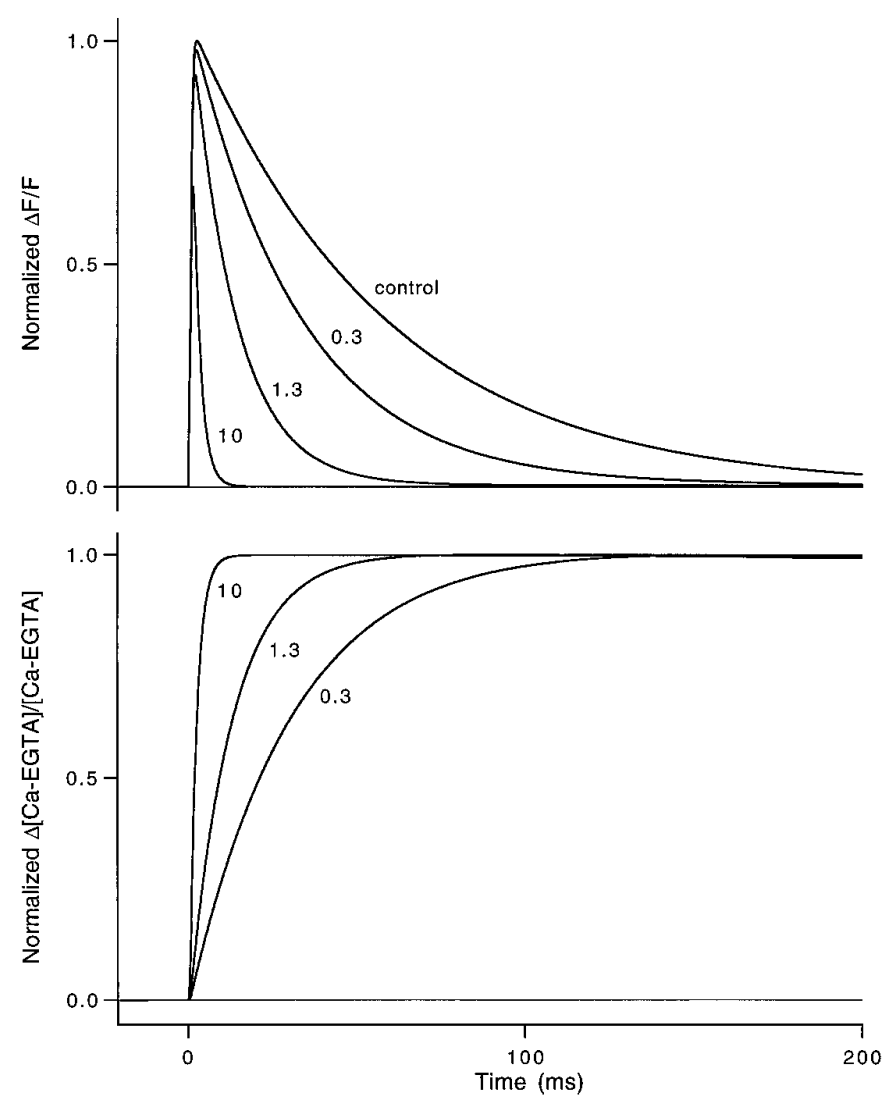

Figure 10. Simulations of the effect of EGTA on $[\mathrm{Ca}]_{\text {res }}$ dynamics. $A$, Calcium transients were simulated as described in the text for control conditions and after the addition of $0.3,1.3$, and $10 \mathrm{~mm}$ EGTA. The $t_{1 / 2}$ of simulated transients is $40,23,10$, and 2 msec, respectively. Peak amplitudes were reduced to 98,92 , and $67 \%$ of control, respectively. The $t_{1 / 2}$ for $\mathrm{Ca}$ transients was similar to the half-rise times $(21,9$, and $2 \mathrm{msec})$ of the Ca-EGTA complex $(B)$ for low, medium, and high concentrations of EGTA. The $\Delta F / F$ transients $(A)$ were normalized to the peak of the control trace, whereas each Ca-EGTA transient $(B)$ was normalized to its own peak to emphasize the time course of EGTA equilibration with calcium.

intracellular EGTA can greatly exceed the concentration of the bath-applied AM form.

To understand how EGTA speeds the decay of calcium, we simulated calcium dynamics (Fig. 10 $A$ ) with a single-compartment model using methods similar to those described previously (Tank et al., 1995; Feller et al., 1996). It is thought that in control conditions, when calcium enters a presynaptic terminal, most of the calcium binds rapidly to fast endogenous calcium buffers, and then $[\mathrm{Ca}]_{\text {res }}$ decays as calcium is extruded from the cytoplasm (Neher and Augustine, 1992; Tank et al., 1995). For our simulations we assumed that the terminal contained a fast endogenous buffer (total $[\mathrm{B}]=1 \mathrm{mM}, K_{\mathrm{B}}=40 \mu \mathrm{M}, k^{+}=5 \times 10^{8} \mathrm{M}^{-1} \mathrm{sec}^{-1}$ ), and calcium was detected with an indicator with properties similar to those of magnesium green (total [Indicator] $=1 \mu \mathrm{M}, K_{\mathrm{D}}=5$ $\left.\mu \mathrm{M}, k^{+}=5 \times 10^{8} \mathrm{M}^{-1} \mathrm{sec}^{-1}\right)$. Levels of indicator in our imaging experiments are likely higher than $1 \mu \mathrm{M}$. This value was chosen to allow examination of the effects of EGTA without the complication of the additional buffer. The effect of EGTA was also observed when higher concentrations of indicator are present in the terminal. A Michaelis-Menton calcium extrusion pump $\left(K_{\mathrm{P}}=10\right.$ $\mu \mathrm{M}, V_{\text {max }}=4.8 \times 10^{-3} \mathrm{M} \mathrm{sec}^{-1}$ ) was added so that the control $\Delta F / F$ transient had a $t_{1 / 2}$ of $40 \mathrm{msec}$, as shown in Figure $10 \mathrm{~A}$.
Appropriate total concentrations of EGTA $\left(K_{\mathrm{EGTA}}=200 \mathrm{nM}\right.$, $K_{\text {EGTA }}^{+}=1.5 \times 10^{6} \mathrm{M}^{-1} \mathrm{sec}^{-1}$ ) were used to give calcium decay times similar to those observed in our experiments (compare Figs. $10 A$ and $5 B$ ). As we observed experimentally, the addition of concentrations of EGTA sufficient to speed the $t_{1 / 2}$ to $2 \mathrm{msec}$ attenuated peak calcium levels.

The key to understanding the actions of EGTA on this time scale lies in realizing that because it is a slow buffer, EGTA takes some time to equilibrate with free calcium. After calcium entry and rapid equilibration with the fast endogenous buffer, calcium begins to bind to EGTA, resulting in a reduction of free calcium levels. The time course of $[\mathrm{Ca}]_{\text {res }}$ decay, until free calcium equilibrates with EGTA, is determined mostly by the time course of calcium binding to EGTA (compare Fig. 10, $A$ and $B$ ). Extending reasoning similar to that of Tank et al. (1995) to the nonequilibrium case, the rapid phase of decay of $[\mathrm{Ca}]_{\text {res }}$ transients is approximated by an exponential decay with a time constant given by:

$$
\tau_{\text {fast }}=\frac{\left([B] / K_{\mathrm{B}}\right)}{\left(V_{\max } / K_{\mathrm{P}}\right)+k_{\mathrm{EGTA}}^{+}[\mathrm{EGTA}]} .
$$

Once calcium has equilibrated with both the endogenous buffer and EGTA, and calcium has been reduced to low levels, the small remaining $[\mathrm{Ca}]_{\text {res }}$ decays slowly with a time constant approximated by the following equation (Neher and Augustine, 1992; Tank et al., 1995):

$$
\tau_{\text {slow }}=\frac{\left([\mathrm{B}] / K_{\mathrm{B}}\right)+\left([\mathrm{EGTA}] / K_{\mathrm{EGTA}}\right)}{\left(V_{\max } / K_{\mathrm{P}}\right)} .
$$

It should be noted that although the control $[\mathrm{Ca}]_{\text {res }}$ transients we detect experimentally are not perfect monoexponentials, the model described above seems to capture the major features of the speeding of $[\mathrm{Ca}]_{\text {res }}$ transients by EGTA.

Note added in proof: Bertram et al. (1996) have recently proposed a model of facilitation in which the time course of facilitation is set both by free calcium dynamics and by the kinetics of one or more high-affinity calcium binding sites.

\section{REFERENCES}

Adler EM, Augustine GJ, Duffy SN, Charlton MP (1991) Alien intracellular calcium chelators attenuate neurotransmitter release at the squid giant synapse. J Neurosci 11:1496-1507.

Augustine GJ, Neher E (1992) Neuronal $\mathrm{Ca}^{2+}$ signalling takes the local route. Curr Opin Neurobiol 2:302-307.

Bain AI, Quastel DM (1992) Multiplicative and additive $\mathrm{Ca}^{2+}$. dependent components of facilitation at mouse end plates. J Physiol (Lond) 455:383-405.

Bertram R, Sherman A, Stanley EF (1996) Single-domain/bound calcium hypothesis of transmitter release and facilitation. J Neurophysiol 75: 1919-1931.

Bittner GD (1989) Synaptic plasticity at the crayfish opener neuromuscular preparation. J Neurobiol 20:386-408.

Blundon JA, Wright SN, Brodwick MS, Bittner GD (1993) Residual free calcium is not responsible for facilitation of neurotransmitter release. Proc Natl Acad Sci USA 90:9388-9392.

Buonomano DV, Merzenich MM (1995) Temporal information transformed into a spatial code by a neural network with realistic properties. Science 267:1028-1030.

Charlton MP, Smith SJ, Zucker RS (1982) Role of presynaptic calcium ions and channels in synaptic facilitation and depression at the squid giant synapse. J Physiol (Lond) 323:173-193.

Claflin DR, Morgan DL, Stephenson DG, Julian FJ (1994) The intracellular $\mathrm{Ca}^{2+}$ transient and tension in frog skeletal muscle fibres measured with high temporal resolution. J Physiol (Lond) 475:319-325.

Cohen MW, Jones OT, Angelides KJ (1991) Distribution of $\mathrm{Ca}^{2+}$ channels on frog motor nerve terminals revealed by fluorescent $\omega$-conotoxin. J Neurosci 11:1032-1039. 
Delaney KR, Tank DW (1994) A quantitative measurement of the dependence of short-term synaptic enhancement on presynaptic residual calcium. J Neurosci 14:5885-5902.

Delaney KR, Zucker RS, Tank DW (1989) Calcium in motor nerve terminals associated with post-tetanic potentiation. J Neurosci 9:3558-3567.

Delaney KR, Tank DW, Zucker RS (1991) Presynaptic calcium and serotonin-mediated enhancement of transmitter release at crayfish neuromuscular junction. J Neurosci 11:2631-2643.

Delbono O, Stefani E (1993) Calcium transients in single mammalian skeletal muscle fibers. J Physiol (Lond) 463:689-707.

Dodge FA, Rahamimoff R (1967) Co-operative action of calcium ions in transmitter release at the neuromuscular junction. J Physiol (Lond) 193:419-432.

Feller MB, Delaney KR, Tank DW (1996) Presynaptic calcium dynamics at the frog retino-tectal synapse. J Neurophysiol, in press.

Goda Y, Stevens CF (1994) Two components of transmitter release at a central synapse. Proc Natl Acad Sci USA 91:12942-12946.

Grynkiewicz G, Poenie M, Tsien RY (1985) A new generation of $\mathrm{Ca}^{2+}$ indicators with greatly improved fluorescence properties. J Biol Chem 260:3440-3450.

Heidelberger R, Heinemann C, Neher E, Matthews G (1994) Calcium dependence of the rate of exocytosis in a synaptic terminal. Nature 371:513-515.

Heinemann C, Chow RH, Neher E, Zucker RS (1994) Kinetics of the secretory response in bovine chromaffin cells following flash photolysis of caged $\mathrm{Ca}^{2+}$. Biophys J 67:2546-2557.

Herrington J, Bookman RJ (1995) Pulse control V4.5: IGOR XOPs for patch clamp data acquisition. Miami: University of Miami.

Kamiya H, Zucker RS (1994) Residual $\mathrm{Ca}^{2+}$ and short-term synaptic plasticity. Nature 371:603-606.

Katz B, Miledi R (1968) The role of calcium in neuromuscular facilitation. J Physiol (Lond) 195:481-492.

Konishi M, Olson A, Hollingworth S, Baylor SM (1988) Myoplasmic binding of fura-2 investigated by steady-state fluorescence and absorbance measurements. Biophys J 54:1089-1104.

Konishi M, Hollingworth S, Harkins AB, Baylor SM (1991) Myoplasmic calcium transients in intact frog skeletal muscle fibers monitored with the fluorescent indicator furaptra. J Gen Physiol 97:271-301.

Kortje KH, Kortje D, Rahmann H (1991) The application of energyfiltering electron microscopy for the cytochemical localization of $\mathrm{Ca}(2+)$ : ATPase activity in synaptic terminals. J Microsc 162:105-114.

Li C, Ullrich B, Zhang JZ, Anderson RG, Brose N, Sudhof TC (1995) $\mathrm{Ca}^{2+}$-dependent and -independent activities of neural and non-neural synaptotagmins. Nature 375:594-599.

Liu Y, Stanley EF (1995) Calcium binding sites of the transmitter release mechanism: clues from short-term facilitation. J Physiol (Paris) 89:163-166.

Llano I, Marty A, Armstrong CM, Konnerth A (1991) Synaptic- and agonist-induced excitatory currents of Purkinje cells in rat cerebellar slices. J Physiol (Lond) 434:183-213.

Llinas R, Gruner JA, Sugimori M, McGuinness TL, Greengard P (1991) Regulation by synapsin I and $\mathrm{Ca}^{2+}$-calmodulin-dependent protein kinase II of transmitter release in squid giant synapse. J Physiol (Lond) 436:257-282.

Luther PW, Yip RK, Bloch RJ, Ambesi A, Lindenmayer GE, Blaustein MP (1992) Presynaptic localization of sodium/calcium exchangers in neuromuscular preparations. J Neurosci 12:4898-4904.

Magleby KL (1987) Short-term changes in synaptic efficacy. In: Synaptic function (Edelman GM, Gall WE, Cowan WM, eds), pp 21-56. New York: Wiley.

McNaughton BL (1982) Long-term synaptic enhancement and shortterm potentiation in rat fascia dentata act through different mechanisms. J Physiol (Lond) 324:249-262.

Mintz IM, Sabatini BL, Regehr WG (1995) Calcium control of transmitter release at a central synapse. Neuron 15:675-688.

Naranjo D, Plant C, Dunlap K, Brehm P (1994) Two subcellular mechanisms underlie calcium-dependent facilitation of bioluminescence. Neuron 13:1293-1301.

Neher E, Augustine GJ (1992) Calcium gradients and buffers in bovine chromaffin cells. J Physiol (Lond) 450:273-301.

Palay SL, Chan-Palay V (1974) Cerebellar cortex. New York: Springer.

Palkovits M, Magyar P, Szentagothai J (1971) Quantitative histological analysis of the cerebellar cortex in the cat. III. Structural organization of the molecular layer. Brain Res 34:1-18.
Perkel DJ, Hestrin S, Sah P, Nicoll RA (1990) Excitatory synaptic currents in Purkinje cells. Proc R Soc Lond [Biol] 241:116-121.

Regehr WG, Atluri PP (1995) Calcium transients in cerebellar granule cell presynaptic terminals. Biophys J 68:2156-2170.

Regehr WG, Mintz IM (1994) Participation of multiple calcium channel types in transmission at single climbing fiber to Purkinje cell synapses. Neuron 12:605-613.

Regehr WG, Tank DW (1991) Selective fura-2 loading of presynaptic terminals and nerve cell processes by local perfusion in mammalian brain slice. J Neurosci Methods 37:111-119.

Regehr WG, Delaney KR, Tank DW (1994) The role of presynaptic calcium in short-term enhancement at the hippocampal mossy fiber synapse. J Neurosci 14:523-537.

Roberts WM, Jacobs RA, Hudspeth AJ (1990) Colocalization of ion channels involved in frequency selectivity and synaptic transmission at presynaptic active zones of hair cells. J Neurosci 10:3664-3684.

Rosahl TW, Spillane D, Missler M, Herz J, Selig DK, Wolff J, Hammer RE, Malenka RC, Sudhof TC (1995) Essential functions of synapsins I and II in synaptic vesicle regulation. Nature 375:488-497.

Sabatini BL, Regehr WG (1995) Detecting changes in calcium influx which contribute to synaptic modulation in mammalian brain slice. Neuropharmacology 34:1453-1467.

Schulz PE, Cook EP, Johnston D (1994) Changes in paired-pulse facilitation suggest presynaptic involvement in long-term potentiation. J Neurosci 14:5325-5337.

Schweizer FE, Betz H, Augustine GJ (1995) From vesicle docking to endocytosis: intermediate reactions of exocytosis. Neuron 14:689-696.

Simon SM, Llinas RR (1985) Compartmentalization of the submembrane calcium activity during calcium influx and its significance in transmitter release. Biophys J 48:485-498.

Smith SJ, Buchanan J, Osses LR, Charlton MP, Augustine GJ (1993) The spatial distribution of calcium signals in squid presynaptic terminals. J Physiol (Lond) 472:573-593.

Stanley EF (1986) Decline in calcium cooperativity as the basis of facilitation at the squid giant synapse. J Neurosci 6:782-789.

Sudhof TC (1995) The synaptic vesicle cycle: a cascade of protein-protein interactions. Nature 375:645-653.

Swandulla D, Hans M, Zipser K, Augustine GJ (1991) Role of residual calcium in synaptic depression and posttetanic potentiation: fast and slow calcium signaling in nerve terminals. Neuron 7:915-926.

Tanabe N, Kijima H (1992) $\mathrm{Ca}^{2+}$-dependent and -independent components of transmitter release at the frog neuromuscular junction. J Physiol (Lond) 455:271-289.

Tank DW, Regehr WG, Delaney KR (1995) A quantitative analysis of presynaptic calcium dynamics that contribute to short-term enhancement. J Neurosci 15:7940-7952.

Tsien RY (1981) A non-disruptive technique for loading calcium buffers and indicators into cells. Nature 290:527-528.

Ullrich B, Li C, Zhang JZ, McMahon H, Anderson RG, Geppert M, Sudhof TC (1994) Functional properties of multiple synaptotagmins in brain. Neuron 13:1281-1291.

Westenbroek RE, Hell JW, Warner C, Dubel S, Snutch TP, Catterall WA (1992) Biochemical properties and subcellular distribution of an N-type calcium channel $\alpha 1$ subunit. Neuron 9:1099-1115.

Westenbroek RE, Sakurai T, Elliott EM, Hell JW, Starr TVB, Snutch TP, Catterall WA (1995) Immunochemical identification and subcellular distribution of the $\alpha$-1A subunits of brain calcium channels. J Neurosci 15:6403-6418.

Winslow JL, Duffy SN, Charlton MP (1994) Homosynaptic facilitation of transmitter release in crayfish is not affected by mobile calcium chelators: implications for the residual ionized calcium hypothesis from electrophysiological and computational analyses. J Neurophysiol 72:1769-1793.

Wu LG, Saggau P (1994) Presynaptic calcium is increased during normal synaptic transmission and paired-pulse facilitation, but not in long term potentiation in area CA1 of hippocampus. J Neurosci 14:645-654.

Yamada WM, Zucker RS (1992) Time course of transmitter release calculated from simulations of a calcium diffusion model. Biophys $\mathbf{J}$ 61:671-682.

Zhao M, Hollingworth S, Baylor SM (1996) Properties of tri- and tetracarboxylate $\mathrm{Ca}^{2+}$ indicators in frog skeletal muscle fibers. Biophys $\mathbf{J}$ 70:896-916.

Zucker RS (1989) Short-term synaptic plasticity. Annu Rev Neurosci 12:13-31. 